Portland State University

PDXScholar

\title{
"Tindersluts" \& "Tinderellas:" Examining Young Women's Construction and Negotiation of Modern Sexual Scripts within a Digital Hookup Culture
}

MacKenzie A. Christensen

Portland State University

Follow this and additional works at: https://pdxscholar.library.pdx.edu/open_access_etds

Part of the Feminist, Gender, and Sexuality Studies Commons, Social Media Commons, and the Sociology Commons

Let us know how access to this document benefits you.

\section{Recommended Citation}

Christensen, MacKenzie A., "'Tindersluts" \& "Tinderellas:" Examining Young Women's Construction and Negotiation of Modern Sexual Scripts within a Digital Hookup Culture" (2018). Dissertations and Theses. Paper 4495.

https://doi.org/10.15760/etd.6379

This Thesis is brought to you for free and open access. It has been accepted for inclusion in Dissertations and Theses by an authorized administrator of PDXScholar. Please contact us if we can make this document more accessible: pdxscholar@pdx.edu. 


\author{
“Tindersluts" \& "Tinderellas:" \\ Examining Young Women's Construction and \\ Negotiation of Modern Sexual Scripts within a Digital Hookup Culture
}

by

MacKenzie A. Christensen

A thesis submitted in partial fulfillment of the requirements for the degree of

\author{
Master of Science \\ in \\ Sociology
}

Thesis Committee:

Emily Fitzgibbons Shafer, Chair

Amy Lubitow

Aaron Roussell

Portland State University

2018 


\begin{abstract}
While a growing body of literature exists examining how intersecting social identities and structural organizations shape the on-campus hookup script (Bogle 2008; Heldman and Wade 2010; Armstrong and Hamilton 2013; Allison and Risman 2014), research examining the impact of technology on the hookup culture has been virtually nonexistent. Addressing this gap, this study adds to a current body of literature on the hookup culture and online dating by exploring how a diverse sample of young women and non-binary, femme individuals understand and negotiate interpersonal sexual scripts through the mobile dating app Tinder. Ultimately, findings from 25 in-depth interviews reveal how Tinder has shaped the sexual scripts of young adult dating into a "hybrid hookup script." Unlike the traditional college hookup culture, which centers the hookup script on fraternity parties, sexual dancing, and drinking, the hybrid hookup script reintroduces traditional dating practices, such as formal dates, into the modern sexual scripts of young adults. Specifically, the hybrid hookup script maintains the traditional gendered expectation that men initiate conversations and dates, while incorporating the patterns of drinking and the expectation of non-relational sex central to the on-campus hookup culture. Nearly all participants engaged in the hybrid hookup script to some extent; yet, women of color were overrepresented among those who eventually opted out of Tinder altogether. In particular, experiences of sexual and racial harassment created an environment in which women of color felt racially objectified and fetishized. As a result, the majority of women of color indicated that they deleted the app and did not intend to
\end{abstract}


go back. Overall, results underscore how the Tinder app may be operating to rearticulate existing hierarchies of gender and race. 


\section{Dedication}

I would like to dedicate this thesis to Terri Christensen and StirFry Jones. 


\section{Table of Contents}

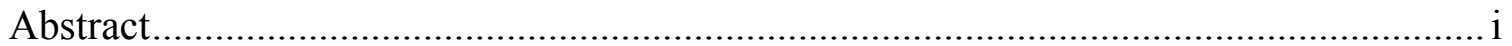

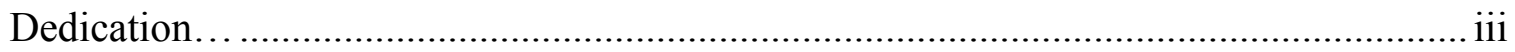

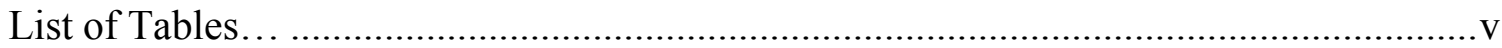

Chapter 1

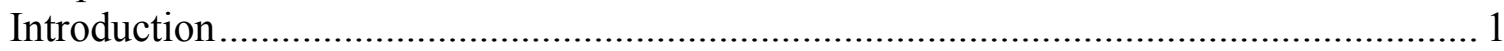

Chapter 2

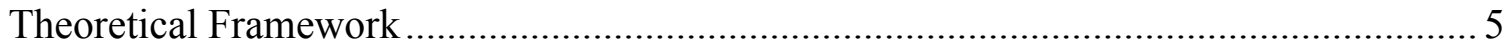

Chapter 3

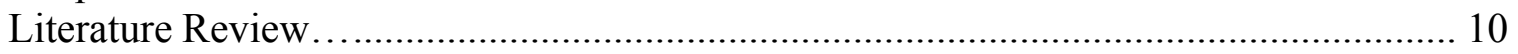

Chapter 4

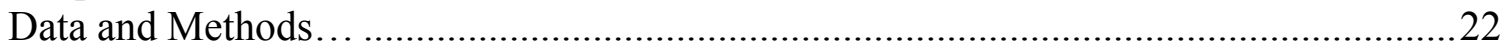

Chapter 5

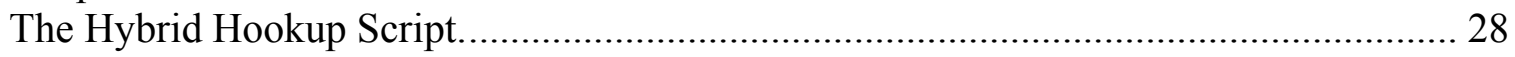

Chapter 6

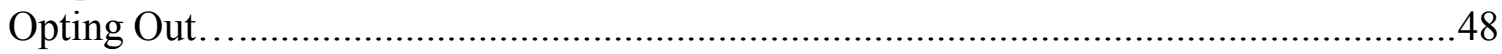

Chapter 7

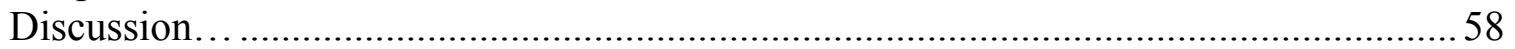

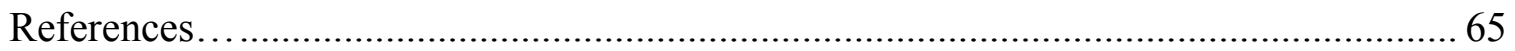

Appendix A

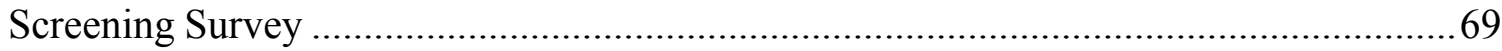

Appendix B

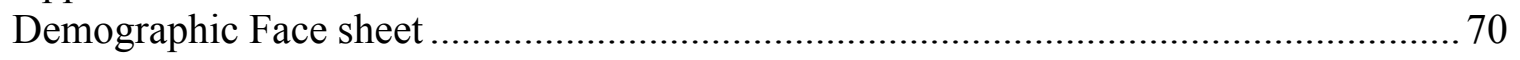

Appendix C

Interview Guide.............................................................. 75 


\section{List of Tables}

Table 1

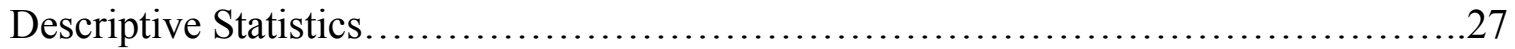




\section{Chapter 1}

\section{Introduction}

Since the development of online dating sites in the early 1990s, scholars have increasingly examined the influence of technology on the formation of intimate relationships (Hobbs et al. 2016; Rosenfeld and Thomas 2012; Quiroz 2013). By 2010, longitudinal survey data indicated that nearly 25 percent of heterosexual couples reported meeting online, making the Internet the fastest growing platform for the formation of intimate relationships (Rosenfeld and Thomas 2012). While traditional online dating sites, such as Match.com and OkCupid, continue to be dominated by users between the ages of 25-45 years (Robert et al. 2009), mobile application (app) developers have sought to bridge the gap between young heterosexual adults and digital dating. By transforming online dating into a quick and informal user-interface, the developers of Tinder, a mobile dating app, have managed to recruit an unprecedented number of digital daters between ages of 18 and 25 years.

In 2011, University of Southern California undergraduates Sean Rad and Justin Mateen set out to create an app that would redefine the boundaries of online dating, bringing opportunities for intimacy to mobile devices with the location-based dating app Tinder. Unlike traditional online dating sites, which require users to fill out questionnaires and develop in-depth profiles, the Tinder UI encourages users to swipe through potential partners like a deck of cards, swiping right for "like" and left for “dislike;" if both users swipe right, it's a "match" and users can begin a conversation. According to Sean Rad, the app was originally intended to "gamify the search for 
partners by emphasizing images and location over personal content" (Grigoriadis 2014). As a result, Tinder initially caught on like wild fire throughout elite college campuses, functioning as a digital extension to an already dominant hookup culture. After Tinder's official launch in 2012, the app generated thousands of users within the first six months, 90 percent between the ages of 18-24 years (Ansari 2015; David and Cambre 2016). By 2014, Tinder had an estimated 50 million users, processing more than a billion swipes left and right a day (David and Cambre 2016).

Today, Tinder has become so prevalent among young cis-gendered men and women that it has generated a new lexicon for digital dating, with terms such as "Tinderslut" and "Tinderella" added to the popular crowdsourced media site Urban Dictionary in 2014. According to the website, a "Tinderslut" is "a slut who uses the app to sleep with men." Conversely, a "Tinderella" is "your dream girl... usually a one night stand. You both live happily ever after, because you never speak again" (Urban Dictionary 2014). While these gendered terms explicitly construct scripts of women as either Tinder sluts or princesses, they also implicitly communicate the sexual expectations associated with the app. In fact, the rise of Tinder has triggered an onslaught of articles from popular media sites and news outlets associating Tinder with the "Dating Apocalypse" and the subsequent rise of a mobile hookup culture (Vanity Fair 2015; Hobbs et. al 2016). As such, Tinder's own marketing campaign emphasizes itself as a supplement the hookup culture- disseminating advertisements that depict young, white, heterosexual matches meeting, drinking, and then waking up together the next morning (Duguay 2016). Thus, Tinder has not only become a new "sexual marketplace" (Goluboff 
2016: 102) for young adults beyond the on-campus hookup culture, but the app has provided participants with a digitalized stage for the development of modern sexual scripts, igniting the need for research that explores the converging relationship between mobile media and young adult sexuality.

Despite the exponential rise of Tinder as a mobile dating platform, the app remains relatively understudied. Since the release of Grindr in 2009, one of the first major hookup apps aimed at connecting gay men based on proximity (Albury and Byron 2016), research on dating/hookup apps has concentrated primarily on same-sex sexuality, safety, and health concerns (Burrell et al. 2012; Goedel and Duncan 2015; Landovitz et al. 2013). Beyond the scope of same-sex sexuality, what remains is a limited collection of research on Tinder and similar mobile dating forums, examining user's motivations, authenticity, and self-presentation (David and Cambre 2016; Duguay 2016; Ranzini and Lutz 2016). While the literature gives breadth to the subject, the primary use of quantitative methods coupled with a focus on college-educated respondents between the ages of 25 to 35 years (Hobbs et al. 2016; Ranzini and Lutz 2016), leaves a gap in our empirical understanding of the experiences of Tinder's younger population.

Addressing these limitations, this study employs data from 25 in-depth interviews to explore the experiences of a diverse sample of young women and non-binary, femme ${ }^{1}$ participants who use Tinder to establish opposite sex relationships. Therefore, I begin to examine young women's experiences on Tinder by drawing on Simon and Gagnon's (1986) Sexual Script Theory to ask: what are the interpersonal sexual scripts of young

\footnotetext{
${ }^{1}$ Noting the diversity of gender identities presented within my sample, I move between both women and feminine Tinder users to describe my overall sample population.
} 
women on Tinder? Accordingly, findings from my analysis unveil the emergence of what I call the hybrid hookup script. This modern sexual script reintroduces traditional dating practices, which are absent in on-campus hookup culture, while maintaining the sexual expectation of a hookup. As such, the hybrid hookup script has developed a new set of social rules for hooking up and dating on Tinder. Further, I utilize the diversity of my sample to examine how the intersection of gender and race compound to integrally shape participants' adoption and enactment of the hybrid hookup script. In this way, findings unveil how women of color experience increased social barriers to frequently enact the hybrid hookup script. Overall, by situating this paper within a broader nexus of scholarship on sexual script theory, I address a gap in our empirical understanding of online dating and the hookup culture by offering the only qualitative analysis that explores the convergence between Tinder and the construction and negotiation of young women's contemporary sexual scripts. 


\section{Chapter 2}

\section{Theoretical Framework}

\section{Sexual Script Theory}

Utilizing a social constructionist approach, Simon and Gagnon's sexual script theory challenged the once-dominant biological perspectives on sexuality, arguing that sexual meanings and desires are not a product of the biological body, but instead, are a product of the social institutions, cultures, and interactions that work in conjunction to regulate normative sexual behavior (Simon and Gagnon 1986). In their work, Simon and Gagnon acknowledge three distinct levels in which scripts are constructed: cultural, interpersonal, and intrapsychic scripts. At the most abstract level of scripting processes, Simon and Gagnon $(1984,1986)$ identify cultural scenarios as the playing field in which sexuality is enacted. They tell us what is appropriate and inappropriate in a given context, shaping the who, what, when, where, and how we have sex (Allison and Risman 2014; Simon and Gagnon 1986; Wiederman 2015). Cultural scenarios are largely informed by social institutions such as government, law, education, and mass media which reflect and perpetuate the sexual expectations of a particular society. At this level, cultural scripts provide a set of rules surrounding sexual behavior. These rules adhere to the attitudes and beliefs of the general society, teaching actors how to behave within a particular cultural scenario. Since cultural scripts vary by context, they cannot predict sexual behavior. Instead, they act as guidelines for social interactions, which actors can use to either reproduce or challenge social norms (Allison and Risman 2014: 57). 
The behavior that is enacted by the individual within a specific social context refers to interpersonal scripting. Through interpersonal scripting, actors engage in "scriptwriting," in which individuals adapt the context-specific guidelines they have learned to a specific social interaction. In this case, the script acts as "the mechanism through which appropriate identities are made congruent with desired expectations" (Simon and Gagnon 1986: 99). When actors adhere to dominant cultural scripts, interactions may play out harmoniously; however, when dyadic sexual scripts do not align, interactions may be more difficult to navigate (Wiederman 2015). Therefore, when cultural contexts differ, actors may be required to use alternative or modified scripts. Further, while interpersonal scripts focus on external behavior, intrapsychic scripting deals with the internal organization and negotiation of sexual desires and behaviors. These scripts include an individual's unique sexual fantasies and memories, and it is within intrapsychic scripting that actors weigh potential difficulties or boundaries involved with interpersonal scripting (Simon and Gagnon 1986; Wiederman 2015). Moreover, this three-tiered approach encompasses the multifaceted and interrelated processes that actors engage with in the construction of sexual identities over the lifecycle. Particularly, Simon and Gagnon note that sexual scripts vary relative to the age of the actors involved. In fact, "the major cultural scenarios that shape the most common interpersonal scripts tend to be drawn from the requirements of adolescence and early adulthood" (Simon and Gagnon 1984: 58). Accordingly, the cultural scripts adopted in early adulthood will likely influence the development of interpersonal and intrapsychic scripts throughout an individual's life course (Sakaluk et al. 2014). Thus, while sexual 
script theory has been effectively deployed as a framework for understanding sexuality over time, researchers have also noted the influence of highly gendered institutions on the formation of sexual identities, resulting in the development of traditional sexual scripts for heterosexual men and women (Alison and Risman 2014; Simon and Gagnon 1986; Sakaluk et al. 2014).

Specifically, research conducted by Sakaluk and colleagues (2014) found that the influence of a gender binary framework promotes specific scripts within heterosexual relationships. According to their study, traditional scripts describe men as more physical in terms of sexuality, while women maintain more emotional and relationship-centric views (Sakaluk et al. 2014: 517). Within traditional sexual scripts, men are viewed as the initiators; they are seen as responsible for taking control of the date and the sexual scenario (Sakaluk 2014). For men, being sexually experienced is seen as a positive attribute and is associated with an increased ability to perform (Oliver and Hyde 1993; Muehlenhard and Shippee 2010; Wiederman 2005). Women's sexual scripts are assessed in contrast to the traditional male role. Traditional scripts for women structure them as the "gatekeepers" of sex (Wiederman 2005). Women are expected to be less sexually active, more focused on building emotional relationships, and are more likely to describe sex as something that "just happened" (Bartoli and Clark 2006; Tolman 2002). Although heterosexual men and women speak about sex and sexuality in ways that reflect traditional gendered cultural scenarios, understandings of appropriate and inappropriate sexual conduct have also been found to vary by racial and ethnic group (Fullilove et al. 1993; Sterk-Elifson 1994). 
In response to a large body of work focusing on the development of sexual scripts among heterosexual white men and women (Tolman 2002; Bartoli and Clark 2006; Alison and Risman 2014; Sakaluk et al. 2014), researchers have begun to document how the intersection of gender and race compound to integrally shape individuals' adoption and enactment of sexual scripts. In particular, by integrating Black feminist thought with Simon and Gagnon's Sexual Script Theory, Stephens and Phillips (2005) examine the trilevel sexual scripting processes of young African American women. In their work, the authors identify how sexual cultural scripts for Black women are shaped by popular media sources that construct contemporary racist images of Black women as The Diva, Gold Digger, Freak, Dyke, Gangster Bitch, and Baby Mama (Stephens and Phillips 2005; Stephens and Few 2005). Not only do these cultural scripts potentially shape how others view and interact with young African American women, but they also have been shown to impact young women's beliefs about physical attractiveness and interpersonal relationships unique to Black women's experiences (Stephens and Few 2005). For example, Wingood and colleagues $(2001 ; 2003)$ found that adolescent African American women who had viewed films and hip hop videos with a high level of African American sexual conduct were more likely to have multiple sex partners and more frequent sex. While this relationship is does not prove causality, the correlation between young women's behavior and exposure to raced and sexed images begins to document how sexual scripts may be impacting the behaviors of young adults. Moreover, while cultural scripts surrounding Black women's sexuality may guide women's sexual behavior, young African American women also learn to re-evaluate cultural level messages (Stephens and 
Phillips 2005: 43). In fact, research shows that young Black adults appear more knowledgeable and sensitive to racial stereotypes compared to their white counterparts (Ryan et al. 1996; Stephens and Phillips 2005). As a result, young Black women and men have been shown to have greater levels of race-based peer and partner preferences (Levy 2000), as ideas about what is appropriate and acceptable sexual behavior vary by racial and ethnic identity. Overall, while sexual scripts have been shown to have specific age, gender, and racial aspects, these various scripts have been relatively upheld overtime. However, changing cultural scenarios, such as the rise of the Internet as a social intermediary and shifting gender norms and expectations, have triggered a growing body of research suggesting that sexual scripts may continue to be evolving (Bogle 2008; Sakaluk et al. 2014). 


\section{Chapter 3}

\section{Literature Review}

\section{From Online Dating to Mobile Hookups}

Over the past decade, scholars have observed the exponential rise of online dating. By 2010, longitudinal data indicated that the internet had become the $3^{\text {rd }}$ most cited way Americans had met their partners, surpassing family, friends, neighbors, and meeting in college (Rosenfeld and Thomas 2012). According to the Pew Internet \& American Life Project, approximately 30 million Americans have used an online dating platform at least once, and among these individuals, 66 percent have gone on a date with someone they met through a dating website (Smith and Duggan 2013). While online dating sites cover a range of sexualities and are increasingly incorporating diverse gender identity selections, the majority of broad-based dating sites are intended for a cisgendered, heterosexual market (Madden and Lenhart 2006). In fact, survey data reveal that approximately 25 percent of heterosexual adult couples reported meeting online (Rosenfeld and Thomas 2012). Given the growing prevalence and visibility of dating sites such as Match.com and OkCupid, researchers seeking to understand the implications of Internet dating have documented the emergence of a new set of rules for digitally mediated interactions among heterosexual adults.

According to research conducted by Mariann Hardey (2008), in order to navigate the social norms associated with meeting potential romantic partners online, Internet daters must learn how to negotiate with the continuum of eDating expectations, where at one end "The Players" distance their online interactions from reality, in a "fantasy-like" 
pursuit of disposable relationships, while "The Wooers" seek to establish a "real connection" in hopes of procuring a romantic relationship beyond the dating website (Hardey 2008: 1115). Unsurprisingly, Hardey's conceptualization of The Players and The Wooers align with traditional gendered scripts. In the study, male respondents (The Players) predominantly express sexually explicit intentions, noting that they obscured their motivations behind traditionally romantic rhetoric. On the other hand, the women (The Wooers) explain how they develop intimate and romantic relationships by pacing their communication with potential partners in order to establish a sense of trust and authenticity before meeting in person (Hardey 2008). Given the disparate goals of the Wooers and the Players, online daters must be able to "meet in the middle" (p. 1121) by compromising their ideal outcomes. Thus, by navigating the expectations of their fellow eDaters, participants learn the rules and behaviors that reduce the risk involved with online dating.

Although both men and women follow a set of shared norms surrounding the order and pace of messages and reciprocity in sharing personal information that mirror hetero-centric traditions of dating (Barraket and Henry-Waring 2008: 159), online dating scripts diverge from traditional in-person interactions in several key ways. First, the "filtering out process" has been shown to be a central aspect to online dating. While similar to in-person evaluations, as eDaters select potential partners on the basis of photos, user self-presentation strategies, and online introductions and interactions, the speed of the process introduces a new type of "hyper sorting" (Davis et al. 2006). Unlike traditional dating practices, hyper sorting enables users to evaluate potential partners at 
unprecedented rates. Second, when compared to meeting a potential partner in person, online daters report a high level of control over the pace and trajectory of their online interactions (Van Acker 2001; Hardey 2002; Ben-Ze've 2004; Barraket and HenryWaring 2008; Hardey 2008). However, using in-depth interviews with online daters, Barraket and Henry-Waring found that while respondents enjoyed an increased sense of agency, they were also aware of the possibility of becoming the subject of others' exercise of control (2008: 159). Finally, unlike in-person dating, when ending online relationships, many eDaters "just press delete" (Hardey 2008) on other daters without any formal explanation, citing a lack of investment in the relationships built online (Hardey 2002; Barraket and Henry-Waring 2008). Thus, while qualitative narratives provide useful in-depth insight into the dating scripts of eDaters, a notable body of empirical work has documented how modern online dating practices may reproduce hierarchies of gender.

Exploring how gendered interactions manifest through online dating websites, research indicates that men are far more likely to initiate contact on online dating websites compared to women, providing men with an initiator advantage (Barraket and Henry-Waring 2008; Kreager et al. 2014; McWilliams and Barrett 2014). According to Kreager and colleagues (2014), online daters who start conversations first are more likely to contact and connect with more desirable individuals, while those who wait to be contacted are more likely to be contacted by less desirable online daters, providing evidence for the initiator advantage. In other words, "by relying on men to initiate a relationship, women often forgo the promise of online dating and are left wondering 
where all the good men have gone" (Kreager et al. 2014: 406). Therefore, women's inaction not only enables heterosexual men to "date up" online, but simultaneously restricts the pool of potential daters available. As a result, online dating becomes a means by which gender inequality in intimate relationships may be maintained as women and men reproduce traditional gendered scripts online. Additionally, in a qualitative analysis of middle-aged and older adults, McWilliams and Barrett (2014) found that distinct gender differences in their experiences. In particular, "women felt obligated to care for the needs of others, while men felt a sense of entitlement to a caretaker" (p. 429). As a result, women, who recognized the disadvantages of marriage, sought out intimacy and companionships outside the traditional confines of marriage and men sought out potential wives and the presumed perks that came with them. Although this work highlights how older women are able to redefine their romantic relationships by using online dating websites, very few women reported meeting older online daters willing to compromise their desires for caretakers.

Moreover, using online dating profiles to examine the relationship between race and online interactions, recent data documents how racial segregation manifests through online dating websites. Although early scholarship theorized that online dating would reduce racial homogamy by de-emphasizing physical proximity as a significant aspect of romantic relationship formation (Barraket and Henry-Waring 2008), the literature on online dating consistently shows that online daters prefer mates who share their ideals of femininity, masculinity, and attractiveness that are often unique to specific racial and ethnic identities (Robnett and Feliciano 2011; Rosenfeld and Thomas 2012: Lin and 
Lundquist 2013). Thus, findings from this work have shown that Black women, Asian men, and to a lesser extent Latino males are the least likely to be messaged or have their messages responded to on online dating sites (Lin and Lundquist 2013; McGrath et al. 2016). In addition, exploring the intersection of gender, race, and education, Lundquist and Lin found that white men and white women with a college degree are more likely to contact and/or respond to white daters with less education than they are to respond to black daters with a college degree (2013: 183). Finally, analyses of racial minorities' preferences indicates that Asians, Black, and Latinos of all genders are more likely to include whites as possible dates than whites are to include them (Robnett and Feliciano 2011: 819), unveiling how exclusion by the dominant group maintains racial segregation in online dating markets.

While a considerable body of literature exists documenting contemporary online dating practices and the sociodemographic characteristics impacting user preference, much of this work homogenizes the various online dating platforms being examined. Addressing the lack of research investigating how different technological platforms impact individuals' romantic relationship formation, Tong, Hancock, and Slatcher (2016) sought to examine how the design features of three different online dating sites impact perceptions of control and user satisfaction. First, their findings indicated that see-andscreen systems (e.g., Match.com), which allow users to browse through all available profiles, provide online daters with an increased sense of control and agency over their online dating decisions. In addition, sites that use the algorithm design (e.g., eHarmony.com), which matches users based on the information they provide through 
questionnaires, boost decision-making satisfaction by offering users a sense of validation for their date selection decisions (Tong et al. 2016: 659). Moreover, by allowing users to view all profiles while integrating algorithmic feedback, blended systems (e.g., OkCupid.com) were shown to produce the highest overall rates of control and satisfaction. Although this work focuses solely on the design features of broad-based Internet dating sites, Tong's findings have important implications for romantic relationships, noting that as couples increasingly use the internet to find potential partners, what site they use to search for a mate may well impact their experiences with online dating.

Over the past decade, online dating sites have increasingly been competing against a rise in mobile dating apps, such as Tinder. Unlike traditional dating websites, Tinder allows users to contact potential partners directly through smart phone devices; and while dating websites such as Okcupid have developed apps to mobilize their online interface, Tinder continues to be one of the most downloaded dating apps in the world (Waxman 2016). As a result, the app has triggered an emerging body of scholarship examining Tinder users' agency, self-presentations, and motivations. Although the app remains relatively understudied, empirical research on Tinder has focused primarily on user authenticity and self-presentation. In research conducted using survey data, Ranzini and Lutz (2016) documented the relationship between self-esteem and deceptive selfpresentation. Their findings show that users who report relatively low levels of selfesteem are more likely to construct inauthentic profiles than users who rate their selfesteem as high. Further, they found users who report an intention to hookup through the 
app are more likely to develop deceptive self-presentations. Conversely, users looking for romantic relationships are more likely to construct authentic profiles (2016: 9). In accordance with these findings, research on pre-match self-presentation techniques show that Tinder users' digital identities are not static, but an evolving process of experimentation based on a desired outcome (Hobbs et al. 2016; Ward 2017). Ward's (2017) qualitative analysis also identified that for participants who sought out relationships, photos were selected in an attempt to balance an ideal/authentic self. These findings shed light on the influence of user motivation in the construction of Tinder profiles.

Research shows that motivations for using Tinder are not clear-cut (Ward 2017). Hobbs' survey data indicated that while 55 percent of respondents reported using the app primarily to find formal dates, 25 percent reported that they used the app primarily for sexual encounters (2016: 6). Further, Ranzini and Lutz (2016) found that although their respondents reported downloading the app for dates, a significant portion of their sample also reported using the app primarily for validation. Their findings also reveal clear gender differences in regards to motivations, with men using the app more for hookups and sex, and women for friendship and self-validation (2016: 12). In a recent analysis of 163 Dutch 18-30 year olds, Sumter and colleagues (2017) found that motivations for using Tinder differed by age and gender. For instance, motivations such as love, casual sex and ease of communication were positively associated with age. In addition, compared to women, men were more likely to report being motivated by ease of 
communication and the thrill of excitement. Overall, among all participants, the love motivation appeared to be stronger than the casual sex motivation.

Moreover, recent scholarship has unearthed contradictory analyses of user agency. In a mixed-methods analysis of Tinder users in Australia, Hobbs found that individuals who actively use the dating app to find sexual partners reported an increased sense of agency and control relative to meeting someone in person. Specifically, their respondents felt that the construction of the app allowed them to set clear sexual boundaries and expectations prior to meeting a match (2016: 7). However, this finding was complicated by David and Cambre's (2016) mixed-methods approach to examining the impact of the Tinder user-interface. According to their analysis, participants reported a desire to use the app to assert individual agency, however, the informality of the app's interface excluded users from freely defining their interactions, as the onslaught of Tinder profiles engendered swiping fatigue. David and Cambre identify the swipe logic as a rationale behind the quick and informal construction of the Tinder user-interface, arguing that the increased viewing speed of profiles facilitates in the establishment of casual relationships by reducing user investment due to an overwhelming database of profiles. While this work is important for understanding how the construction of the Tinder design features may be influencing mobile dating outcomes, the sample populations from these studies were predominantly drawn from users between the ages of 25 and 35 years, leaving a gap in the analysis of Tinder's younger users. Therefore, in the following section I address the literature on the on-campus hookup script in order to better 
understand the culture surrounding contemporary young adult sexuality and dating practices.

\section{The College Hookup Script}

Since the 1960s and 1970s, scholars have observed a transition in America's gender structure. With an increase in accepting attitudes towards premarital sex, a rising age of first marriage and childbirth, and a growing number of women graduating from college, the traditional gender expectations that dominated the 1950s began to shift (Allison and Risman 2014; England et al. 2007). These changing gender ideologies prompted scholars to investigate the dating habits, relationships, and sexual practices of American students across college campuses. The research unveiled the emergence of the hookup culture, which now acts as the dominant sexual script for young heterosexual college students (Allison and Risman 2014; Bogle 2008). Although the term "hookingup" remains vague amongst the literature, most research identifies the term as representing a variety of sexual behaviors outside of a committed relationship (Kalish and Kimmel 2011; Reid et al 2011). Compared to traditional dating scripts, the hookup script implies a lack of formality, as well as a reordering of sexual activity, where sex precedes a romantic relationship, if a romantic relationship is established at all (Bogle 2008; England et al. 2007). Additionally, Bogle's analysis of two college campuses identified the influence of fraternity parties, alcohol consumption, and sexual dancing as central to the hookup script. Notably, provided that peers communicate the sexual norms and expectations surrounding the hookup script, undergraduates have been shown to overestimate their peers' approval and participation in hookups (Barriger and Velez- 
Blasini 2013; Berntson et al. 2013). "These perceptions influence the interpersonal sexual script in the college context” (Berntson et al. 2013: 150). As a result, studies indicate students may be reluctantly participating in an on-campus hookup culture as perceptions of the hookup norm create pressure for students to engage (Bogle 2008; Heldman and Wade 2010).

While the development of the hookup script hints at a shift towards more egalitarian sexual relationships, research on the outcomes of hooking up reveal distinct gender differences in initiation, agency, and stigma. According to a mixed methods analysis conducted by England (2007), despite the finding that women and men initiate conversations and dancing equally, men are much more likely to initiate sexual interactions. These findings were substantiated by Bogle (2008) who highlighted the tendency for hookups to take place at fraternity parties, and Goluboff (2016) whose research on the impact of cellphones found that men were more likely to initiate "sex talk" and "booty calls" through text messages. Additionally, while research on women's sexual agency implies that women within the hookup culture are not as comfortable communicating specific sexual needs or desires compared to women in relationships, findings also show that men are less likely to reciprocate oral sex and hand stimulation during hookups (England et al. 2007). Consequently, women experience fewer orgasms than their male counterparts during hookups (England et al. 2007; England et al. 2012). These findings may be attributed to the internalization of the sexual double standard within the hookup culture. According to Reid (2011), the dominant sexual scripts that stereotype men as driven by sex and women as driven by relationships leads to a double 
standard that relegates women to sex within committed relationships while men are free to partake in casual and/or committed sex. This sexual double standard results in the maintenance of a gender hierarchy in which men's pleasure is prioritized over women's, whereas women's sexuality is policed by hegemonic gender norms that consider sexual women to be "loose" (Reid et al. 2011; Tolman 2002).

Although research on the hookup script primarily centers on the experiences of young white, middle-class college residents, a small body of research has examined how intersecting identities shape young adults' experiences in the hookup culture (Allison and Risman 2014; Hamilton and Armstrong 2009). Not all college-age individuals engage in hookups equally. Research shows that older students are more likely to "age out" of the hookup script over time, as older students replace casual sex with more serious relationships (Armstrong and Hamilton 2013; Bogle 2008). Moreover, in an analysis of the interrelationship between gender and class, Hamilton and Armstrong's ethnographic study found distinct class differences between women in the hookup culture. On one hand, women from more privileged backgrounds experience "double-binds" (2009: 602), in which cultural expectations surrounding young adult sexual behavior were reflected by hookup culture norms. On the other hand, women from less-privileged backgrounds felt that the sexual climate on campus was foreign and even hostile in regards to their traditional beliefs about sexuality (2009: 699). Further, Allison and Risman's (2014) study of students at a commuter university demonstrates how race, class, and campus residence impact student's negotiations of the hookup script. Their analysis reveals how students who live outside of college housing are less likely to adopt the hookup script 
relative to their residential counterparts. This residential division reflected clear racial and class differences, as students of color and students from lower socioeconomic backgrounds were more likely to be spatially separated from the on-campus hookup culture. By examining the influence campus residence, Allison and Risman underscore how institutional factors shape young men and women's enactment of the hookup script, emphasizing the necessity of structural support in students' adoption of modern sexual scripts. Thus, for young men and women, the college campus informs a cultural scenario in which the hookup script is perceived as normalized and accepted. However, as a highly gendered institution, colleges maintain a hookup culture framed within traditional gender expectations, and while there is evidence of a declining sexual double standard amongst female students (Hamilton and Armstrong 2009), research on the hookup culture remains relatively constricted by the raced and classed boundaries of campus life.

Taken together, the literature on the hookup culture and online dating bring attention to the social structural contexts in which interpersonal sexual scripts operate. Yet researchers have not bridged the gap between the hookup culture and dating apps. Given that technologies, such as Tinder, have almost undoubtedly shaped our culture today, "an important step for modern sexual script research should be examining current cultural scenarios" (Sakaluk 2014: 518). As such, this study considers the extent to which the hookup script is understood and negotiated through the Tinder app. Therefore, by examining the impact of intersecting social identities on the adoption and enactment of young women's sexual scripts, this research adds to the literature on the hookup culture 
by underscoring the convergence between technology and young women's sexual and romantic relationship formation. 


\section{Chapter 4}

\section{Data and Methods}

Examining the convergence between the hookup culture and the emergence of the Tinder app, I interviewed 25 feminine Tinder users. Due to recruitment criteria that asked for individuals who swipe for men on the app, I ended up with a sample that consisted of 23 self-identified women and 2 Non-binary, femme individuals. Participants who identified their gender as nn-binary, femme described that while they presented a feminine identity, their internal gender identity did not align with the binary options offered by dominant U.S. society. Since the Tinder interface directs all users, regardless of their indicated gender, to choose between men and women, the feminine Tinder users in my study selected to be shown under the category of women, therefore I include them in my sample. As stated previously, I move between the use of the term women and feminine Tinder user, in order to represent the varied gender identities of my participants. The strength of this research lies in the use of semi-structured in-depth interviews that allowed me to elicit more open narratives in which gendered expectations, attitudes, and ideologies were present. While this interview technique facilitated a reflexive conversation that captured the complexities of my participants' experiences, an interview guide was used to maintain enough structure to code for recurring patterns among participants' responses. In addition to in-depth interviews, there was a brief guided observational component to the research. During the interviews, participants were asked to show me how they operated Tinder; including how they swipe for matches, how they construct their profiles, and how they use the app to communicate with potential partners. 
All participants in the study were given a $\$ 10$ gift card to a local grocery store prior to starting the interview.

\section{Data Collection}

The data for this study comes from a total of 25 in-depth interviews and observations conducted with feminine-identified Tinder users between 18 and 26 years old, who swipe for men on the app, and currently live in the Portland metro area. Participation requirements were developed to create parallels with existing literature on women in the hookup culture, while diverging from the boundaries of the traditional college campus. Consequently, I made an intentional decision to exclude women who currently lived in college housing (i.e., dorms or sororities), as campus residences provide a unique and highly gendered environment for young women to access the hookup culture (Allison and Risman 2014; England, Shafer, and Fogarty 2007). Due to the heteronormative construction of the Tinder user-interface, the sample was also limited to Tinder users who swiped for men in order to delineate a pattern of how participants negotiated sexual/romantic relations with men on the app. Additionally, my focus on young feminine Tinder users is informed by the understanding that women between the ages of 18 to 26 years old are "at a critical developmental stage in which they are exploring aspects of their sexual selves and experimenting with sex, love and relationships (Sakaluk et al. 2014).

The recruitment approach for this study was two-pronged. Initial recruitment took place largely through announcements to Introduction to Sociology courses at Portland State University. At these announcements I briefly covered the topic of my study, 
participation requirements, and provided small flyers with my contact information and a link to a Qualtrics screening questionnaire. Secondary recruitment took place through the posting of flyers throughout university and community college campuses, as well as through digital flyers posted to public social media sites, such as Instagram, Facebook, and Twitter. Once initial interviews took place, several interviewees mentioned having friends that were also interested in participating in the study, and asked permission to share my contact information with their friends. As a result, 7 participants were recruited through snowball sampling.

Data Analysis

All 25 semi-structured, in-depth interviews were conducted from July of 2017 to February 2018 in public spaces at the participant's request. Interviews lasted from 30 to 85 minutes, with an average of 52 minutes. Prior to the interview process, participants were given a consent form to review and sign, and a brief demographic questionnaire to fill out (see appendix). The demographic questionnaire that covered questions on gender and sexual identity, race, educational attainment, parent's education, etc. Notably, following Allison and Risman (2014), I proxy parent's educational attainment for social class background. In this way, a working class background is defined as one in which none of the parents have completed a college degree; middle class participants had at least one parent with a college degree; and upper class participants had at least one parent with an advanced degree or higher ${ }^{2}$. Once the interview began, participants were asked a series of open-ended questions regarding their experience using the Tinder app. While

\footnotetext{
${ }^{2}$ While I acknowledge that this is an imperfect measure of social class background, my division along parents educational attainment follows other qualitative coding of social class (Allison and Risman 2014)
} 
interview questions varied by participant, the interview guide (see appendix) prompted four subsets of topics. The first part of the interview included an observation of the participants Tinder profiles. At this point, users were asked questions surrounding the selection of photos, description of bios, and age and distance choices. During this time, I took field notes that documented how participants navigated and moved through the app. The second set of questions focused on the exchange of messages with 'matches;' questions addressed initiation of conversations, sex talk, handling of harassment, and negotiating 'meet-ups' or dates. The third set of questions covered Tinder dates and hookups, while the fourth set examined more general attitudes and beliefs about the Tinder app. All interviews were audiotaped and personally transcribed, as were all field notes taken during the brief observational period. Transcripts were de-identified and pseudonyms are used to protect the confidentiality of the research participants. After all interviews were transcribed and downloaded to the qualitative analysis software Dedoose, I used an inductive approach (Thomas 2006) for analyzing the data in order to code the transcripts for emerging themes.

Table 1 presents participant demographics with associated pseudonyms. Overall, interviews were conducted with predominantly self-identified cis-women, with 8 percent identifying as non-binary, femme. Amongst participants, 60 percent of the sample identified as white and 40 percent identified as a person of color. Although all participants swiped for men on Tinder, 72 percent identified as heterosexual and the majority of the sample ( 80 percent) were single at the time of the interview. Nearly half (48 percent) of the participants were between 18 and 20 years of age. While 72 percent 
were currently enrolled in a college program, 56 percent indicated that they had at least some college education. Using parent's educational attainment as a proxy for social class background, participants' class background was relatively evenly distributed with 44 percent of the sample coming from a working class background, 32 percent from a middle class background, and 24 percent from an upper class background.

Table 1: Participant Demographics

\begin{tabular}{|c|c|c|c|c|c|}
\hline Participant & Gender Identity & Sexual Identity & Race/Ethnicity & Class Background & Age \\
\hline Aleia & Woman & Bisexual/Fluid & Black/Native American & Working class & 24 \\
\hline Chloe & Woman & Heterosexual & White & Working class & 26 \\
\hline Kaelyn & Woman & Heterosexual/Poly & Black/African American & Middle class & 24 \\
\hline Laura & Woman & Heterosexual & White & Working class & 25 \\
\hline Carly & Non-binary, femme & Queer & Arab American & Upper class & 21 \\
\hline Olivia & Woman & Heterosexual & White & Upper class & 22 \\
\hline Rebecca & Woman & Heterosexual & White & Working class & 23 \\
\hline Em & Woman & Heterosexual & White & Middle class & 24 \\
\hline Amy & Woman & Pansexual & White & Middle class & 19 \\
\hline Rosa & Woman & Heterosexual & White & Middle class & 18 \\
\hline Mikayla & Woman & Heterosexual & Asian American & Working class & 21 \\
\hline Isabella & Woman & Heterosexual & White & Working class & 18 \\
\hline Lily & Non-binary, femme & Pansexual & White & Working class & 18 \\
\hline Sophia & Woman & Heterosexual & White & Upper class & 20 \\
\hline Elena & Woman & Heterosexual & White & Upper class & 20 \\
\hline Gemma & Woman & Pansexual & White & Middle class & 25 \\
\hline Charolett & Woman & Bisexual/Fluid & White & Upper class & 19 \\
\hline Jade & Woman & Heterosexual & White & Working class & 23 \\
\hline Ashlynn & Woman & Heterosexual & White & Working class & 20 \\
\hline Fatima & Woman & Heterosexual & Persian & Middle class & 18 \\
\hline Ana & Woman & Heterosexual & Latina & Working class & 19 \\
\hline Deja & Woman & Heterosexual & Black & Working class & 18 \\
\hline Lucia & Woman & Heterosexual & Latina & Upper class & 23 \\
\hline Talia & Woman & Heterosexual & Pacific Islander & Middle class & 20 \\
\hline Lupe & Woman & Questioning & Black/Latina & Working class & 24 \\
\hline
\end{tabular}

Note: All participants in the study who self-identitfied as a woman cis-gendered women $(\mathrm{N}=25)$

It is important to consider the role of the researcher when conducting qualitative work. Given that I am a 23-year-old white, cis-gendered woman, my social identity was 
reflected by many of the participants in my study. Although I identify as queer, I did not explicitly disclose this identity to my participants (as none of my participants asked me about my sexual identity directly). However, due to my performance of emphasized femininity, I often pass as heterosexual, and therefore my sexual identity may have been presumed to be straight. Due to presumed parallels between my social location and many of my respondents, participants often indicated that they viewed me as part of a similar community, with statements such as "you know how it is," or "I'm sure you understand." While this interpretation of my identity may have created a more comfortable environment for participants, as one woman noted, "I'm really glad you're not an old man" (Jade), it may have also led them to assume that I shared a common knowledge of particular experiences, potentially stunting their elaborations of certain events. Thus, in moments where I felt that participants were assuming my knowledge of a situation, I made an effort to ask probing questions to elicit more detailed descriptions of the events. 


\section{Chapter 5}

\section{The Hybrid Hookup Script}

Congruent with popular media outlets crediting Tinder with the rise of a digitalized hookup culture (Mason 2015; Hobbs et al. 2016), nearly all of my participants $(\mathrm{N}=25)$ understood Tinder as a hookup app. Throughout interviews, participants invoked the idea that the design features of Tinder "gamify" sex and dating for young adults, enabling the develop of fast and informal relationships. Thus, while scholars have previously focused on the centrality of the college campus in maintaining the hookup culture (England et al. 2007; Allison and Risman 2014), findings from my analysis show how the Tinder app has exported the hookup culture, subsequently shaping the hookup script for young women and non-binary, femme individuals. As a result, the majority of participants acknowledge the development of a new set of rules for dating and hooking up on Tinder. In fact, of the 21 out of 25 women who had been out on a Tinder date, 16 engaged in at least one Tinder hookup. Aligning with the literature on the on-campus hookup script, participants defined hooking up as a variety of sexual behaviors, from making out and fondling to oral and penetrative sex, that take place outside of a committed relationship. As such, interviews reveal the emergence of what I call the hybrid hookup script. This digitally mediated hookup script reintegrates traditional dating practices, which are absent in on-campus hookup culture, while maintaining the expectation of a hookup. Specifically, the hybrid hookup script follows a pattern in which men are expected to initiate conversations and formal dates through the app, alcohol is consumed on the date, a hookup is expected, and the relationship concludes abruptly and 
without explanation when one actor "ghosts" - a term I address in detail below. In this way, the hybrid hookup script maintains the traditional gendered sexual scripts that assert that men should be the initiators of formal dates and relationships while integrating the patterns of alcohol consumption and the presumption of a hookup that are central to an on-campus hookup culture. Overall, my findings document how the Tinder app serves as a digital pathway for the construction of contemporary sexual scripts.

\section{The Hybrid Hookup Design}

Within an on-campus hookup culture, actors engage through face-to-face interactions; however, the hybrid hookup script is developed within the digitally mediated environment of the Tinder app. Unlike residential college campuses, this environment constructs a unique mobile playing field for the construction and negotiation of young women's sexual scripts, setting the stage for the enactment of the hybrid hookup script. For instance, when asked what she knew about Tinder before downloading the app, Ashlynn (white) noted, "Tinder is renowned for being this app where everybody says they 'just want to meet people,' but we obviously all know it's a hookup app." In a similar vein, Rebecca (white) explained,

I just thought the idea of swiping on someone made it all hookup based, which is I think is a very common thing to be said. So ya, I didn't think there would be a good variety of guys actually looking for actual relationships and not just wanting to hook up with girls.

Compared to other dating apps, such as OkCupid or Bumble that allow users to create more in-depth dating profiles, Tinder was consistently considered the go-to app for 
hookups and casual encounters. Reflecting on how Tinder differed from similar dating apps, Kaelyn (Black) explained, "I feel like Bumble is a commitment, it's like 'I'm dating!' and Tinder is so easy, it's more like 'I'm trying to fuck."' Similarly, Charlotte (white) noted,

On OkCupid, I guess it feels more like for relationships... it's kind of like a time suck. You have to craft a really long profile and there are a ton of questions... I think people are more interested in dating on there because you really have to put so much work into it and you have to craft the best profile because you want a good match. So I don't know, I prefer that Tinder is a phone app, it's so easy and it's definitely more casual because you don't have to do that much work, it's just swiping so fast.

Both Kaelyn and Charlotte's interactions with Tinder unveil how participants associate the design features of the app with promoting informal interactions over more serious relationships. Further, participants explained that because the process of creating a profile on Tinder is less involved compared to dating apps that require users to complete lengthy questionnaires and develop more in-depth profiles, Tinder relationships were perceived as less formal.

Interestingly, participants understood Tinder as a hookup app; yet, the majority of women did not download Tinder to find hookups. Instead, women acknowledged that while the informal design features promoted hookups, they reconciled this disjuncture with the enjoyment and social gratification they received from "playing" the Tinder game. Notably, while motivations for use were complex and multifaceted, all participants indicated that, at least in part, they downloaded Tinder as a source of entertainment and social gratification. In fact, reflective of Sumter's (2013) conceptualization of Tinder as 
the "gamification" of dating, women often compared the process of swiping through profiles on Tinder to playing with a deck of cards. As Sophia (white) explained,

I don't really think I'll find a partner on the app, so I find myself giggling at the fact that I'm playing with it in the first place. But then you get a right swipe and then in your mind is like 'they were really attractive and they also liked me and that's so cool, I'm attractive' - continue swiping.

Not only does this game keep women entertained, but it also becomes a system of instant satisfaction. As Aleia (Black/Native American) recalls, "It's kind of like a video-game. It's a tricky thing with your brain, where you're like 'what's next?' It's the pure intrigue of what's next that keeps me wanting to use it." Guided observations also revealed how the design features of Tinder encourage users to swipe through matches at increased viewing speeds. As users swipe through profiles, they screen potential matches in a matter of seconds. Eventually, as participants swipe right, the joy of matching with another user kept participants Tindering. Although women enjoyed receiving matches and viewed the process as an "instant ego boost" (Talia, Pacific Islander), the brevity of the interface often kept participants from developing an emotional investment to potential partners during the selection process. When asked about why assumed she would not establish a committed relationship through Tinder, Lucia (Latina) explained,

I think since you can swipe so fast and go through people so fast and just dismiss so much by just the first picture, then how can you really invest in any of these relationships. Especially swiping through, I pick out things that I don't like so fast and they are so stupid, like you're wearing a white shirt—left. It's weird and it's for reasons I would never judge anyone in real life for. It's too easy. 
Amy (white) also related the informality of her relationships on the app to Tinder's design features,

I think because the app is so impersonal in some ways, I feel very detached from the connections that I am making... Maybe that contributes to the rise of this hookup culture. Nobody really has a stake in the relationships that they're creating using Tinder, you can just be whoever you want then delete the person off the app and walk away and never have to see them again.

For Amy and Lucia, the immediacy of Tinder allows them to disconnect from the reality of the relationships they establish. In this way, the Tinder platform constructs a depersonalized environment where users do not feel inclined to invest in more committed relationships. Notably, while Amy explicitly identifies the relationship between the design features of Tinder and the hookup culture, her narrative also underscores how the app has developed new guidelines for digital interactions and gendered sexual scripts among young adults.

\section{Gendered Initiations and "Tinder Etiquette"}

Operating within the digital environment provided by the app, participants outlined a similar set of norms and expectations surrounding dating and hooking up on Tinder. According to Lily (white), "There's definitely a learned routine to talking to someone online and seeing if they want to meet in real life, so Tinder helped me develop that skillset to navigate dating these days." Given that Tinder only allows users to send a message after a match has been reciprocated, women reported a reduced need for social cues that would indicate romantic/sexual interest. Therefore, participants explained that 
matching with another user communicated a mutual attraction and/or sexual interest had been established. As Chloe (white) described,

When you're on Tinder and you match with someone, you already know that they find you attractive and you find them attractive, like all of these things are sort of already a given. Whereas if you meet someone in person, there's not that kind of clarity.

Although this environment may hint at a leveled playing field since both users have a presumed mutual interest based on the receipt of a match, the hybrid hookup script continues to uphold traditional sexual scripts that encourage men to initiate conversations and relationships. Among the women in my study, the majority reported that they preferred men to initiate contact. In fact, 19 out of 25 of my participants reported that they had never initiated a conversation or date through Tinder. Markedly, among the minority who chose to start conversations through the app, gender beliefs about how women are expected to behave on Tinder were communicated by matches. For instance, when asked about her initial interactions with men on Tinder, Aleia (Black/Native American) expressed how she learned the rules associated with the hybrid hookup script,

When I first started using the app I didn't know the Tinder etiquette, so anyone who I thought was really cute I would message them once we matched. But every guy I messaged seemed confused that I would message first. So obviously, I was doing something wrong. So after like two weeks into using the app I stopped messaging first.

For Aleia, messaging matches became an interactional process in which men policed her non-normative gender behavior. Eventually, as she learned the rules associated with 
interacting with men on Tinder, she adjusted her behavior to allow men to initiate conversations and dates. Aleia was not the only participant to explicitly mention "Tinder etiquette." Several women expressed similar experiences where interactions with friends and matches taught them how to appropriately enact the hybrid hookup script. When asked how conversations were started, Amy (white) noted,

I would actually initiate a lot of them and I didn't think it was weird until guys started telling me that it was weird. Just because when I would swipe right and get a match, it just made sense to message them immediately... But lately I've been messaging first way less because I guess it's not Tinder etiquette.

The shared rules that encouraged women and feminine Tinder users to adhere to traditional sexual scripts (Sakaluk et al. 2014) were not seen by participants as unproblematic. When asked about her experiences talking to men on the app, Fatima (Persian) explained,

Tinder seems like this battleground of gender, girls trying to gain a strong hold of guys but guys inevitably come out on top, because it gives guys this weird power... I think it's related to this notion that I don't initiate conversations, so they're allowed to control the conversation. I'm not okay with the power it gives them, but I also contribute to that.

This "battle of the sexes" perspective presents the hybrid hookup script at odds with women's objectives on the app (Reid et al. 2011). Fatima was well aware of the initiator advantage (Barraket and Henry-Waring 2008; Kreager et al. 2014; McWilliams and Barrett 2014) maintained by men on Tinder, yet gendered interactional processes prevented her from transgressing traditional sexual scripts out of fear of being labeled as 
"annoying" or "too forward." Moreover, participants were also reluctant to message men first as a way of avoiding coming off as too eager for romantic relationships. Notably, for some women of color, cultural expectations surrounding traditional courtship practices simultaneously influenced their mobile interactions, as Ana (Latina) described, "I wouldn't hit them [men on Tinder] up first. But I feel like that has more to do with my culture. In my home, women are expected to be talked to- women don't start the conversations." Further, Laura (white) discussed an awareness of the traditional scripts associated with dating on Tinder when she explained,

Well I know that this is totally old school or traditional or maybe sexist, but I usually want the guy to ask me on a date, like I don't want to have to ask him unless we were talking forever. But then again, if we were like still talking forever and he still hasn't asked me, then I'm gonna be like, 'okay buddy...' So I would say they usually ask me out. Usually something kind of generic or cliché, like 'let's meet up for a drink.' Which is fine because it's easy to talk over drinks rather than like, sober. So if we have been talking for exchanging messages for a week... and there's a week between each message, then he is probably never going to ask you out.

For Laura, allowing men on Tinder to initiate messages and set the tempo and pace of conversations also positions her matches to be the initiators of Tinder dates. Thus, the reintegration of traditional practices continue as the hybrid hookup script reintroduces formal dates into young adult sexual scripts.

Tinder Dates, Drinks, and "Shitty Dick"

Unlike the on-campus hookup culture where students meet informally at parties or in dorm rooms (Bogle 2008), participants report that in-person Tinder dates are a required aspect of establishing romantic/sexual relationships through the app. However, formal 
dates were used less as a means to get to know one another, but as a strategic process of verifying authenticity. It is during Tinder dates that women have an opportunity to measure a match's in-person identity against their Tinder profile. Typically this process involves meeting in a public and well populated area, in order to ensure safety, then going for out for drinks. Participants indicated that they intentionally avoid going out for dinner or to a movie to maintain the informality of Tinder dates and keep initial interactions abbreviated. Among participants who were under 21 years of age, dates were more likely to start at a coffee shop or park and eventually lead to the match's home, where matches would typically drink or smoke cannabis/marijuana. After Tinder dates and drinks, participants reported that hookups generally took place at the home or apartment of their match.

Similar to the on-campus hookup culture, drinking was an essential aspect of the hybrid hookup script. As Em (white) recalled, “I'm usually 4 drinks down when I decide I'll sleep with him." Additionally, when asked how she decided if she when to hook up with a match, Ashlynn (white) explained,

I think it depends on how much alcohol I consume on the date. I feel like alcohol helps reduce the nervousness and if you're both drinking then you're both doing a mutual thing together. I don't know, when you go and have drinks with somebody its good, you're just going to grab drinks and its casual and it's not like were going out to dinner and I'm going to have to spend two hours with you. If I can have one drink with you and I don't like you, then that's it. But if there's a connection then you can get more drinks and then that's your gateway intowe're probably going to have sex. 
Among women who fully enacted in the hybrid hookup script, hookups predominantly took place back at the house or apartment of their male Tinder date. For some, this was a strategic decision that kept their match from knowing where they lived or the neighborhood they lived in. But for others, going back to the home of their match was a matter of adhering to the normative expectations of the hookup script in which men take the lead on initiating sexual contact in the relationship. As Sophia (white) indicated, "If I hookup with a guy, we usually go to their house which makes me a bit nervous cause you don't know how they are actually going to be and you're in their space. But I guess you just have to hope for the best, which is not good." Sophia was not the only participant to complain about the habit of following a match back to their place. When summarizing a typical Tinder date, Jade (white) reflected on the time and financial consequences of going back home with a match,

We usually meet up for beers, I have rarely met up with someone to do something not alcohol related, and then we usually have a good enough time where I decide I'd be willing to fuck them, like a drink or two in. Then you go to another bar pretending that you two are still getting to know each other, and then we take an Uber to his house. I say this to myself all of the time, but I need to stop always going to their place, because I fucking hate it for so many reasons. But just the physical act of getting back to my place sucks. Like I should be a smart whore and bring him back to my place so I don't have to take a \$10 Uber across town. I'm still working out the logistics, 'cause I can't keep spending $\$ 10$ on shitty dick.

Jade was aware of how the hybrid hookup script had become routine in her dating life and although she asserted that she hoped to eventually change her behavior on the app, she explained that the hybrid hookup script had become the dominant sexual script in her life. Notably, a number of women felt confined by the hybrid hookup script. While they 
enjoyed the process of dating potential partners off Tinder, the outcomes of their Tinder dates often left them feeling disappointed. Like Jade, many feminine Tinder users did not enjoy their hookups. Throughout interviews, participants described Tinder hookups as "mediocre at best" (Em, white), and expressed feelings of "embarrassment" (Lucia, Latina) and "desperation" (Laura, white) associated with dating and hooking up on the app. While some participants attributed this an internalization of a "Tinderslut" stigma that makes them feel "dirty" or "cheap" (Mikayla, Asian American) for using Tinder, many women indicated that the perception that hooking up is the norm on Tinder created pressure that influenced their behavior to hookup regardless of their intentions.

\section{The Hookup Expectation}

Regardless of participants' motivations and behaviors on the app, the dominant reputation of Tinder established beliefs about how participants were expected to behave. These beliefs were communicated to women through interactions with friends and matches who relayed the script that Tinder is meant for hookups. Notably, participants indicated that they primarily downloaded Tinder with the intent of meeting new people or potential partners, but not explicitly for hookups. However, interviews revealed that Tinder's reputation and the subsequent hybrid hookup script confined their ability to transgress the presumption of non-relational sex. In fact, while 16 out of 25 of my interview participants reported at least one Tinder hookup, 11 of these women reported that they did not intend to hookup with their Tinder dates. This finding underscores the bind that participants experience between a desire for more committed relationships and the social expectation of a hookup. For example, when reflecting on her experiences with 
hookups Lupe (Black/Latina) confessed, “To be honest, I don't really ever go into it just looking for a hook up, like I secretly hope that there's more to it." Similarly, Rebecca (white) stated, "I mean I am always kind of thinking I'm going to meet the love of my life, so that's always in the back of my head. I really don't just want to fuck, but I know that's what's probably going to happen." For Rebecca, the act of creating a Tinder profile inherently implicated her within the hookup culture, as she justified her engagement by stating, "You know what you're getting yourself into when you sign up."

Coupled with the reputation of Tinder as a hookup app, participants also invoked the idea the idea that as young women, they should be focusing on individual growth instead of investing in relationships. In this way, Tinder provides a platform that aligns with the cultural expectations of young adult sexuality. When asked about her experiences trying to date on Tinder, Gemma (white) noted,

It just feels weird that you'd want something more from a person than just hooking up with them off Tinder. Our society already tells you that you're weak if you're already searching for a partner: you're seen as co-dependent...With Tinder it's the same thing, if you were to post: "looking for something serious," everyone would be like "that's weird, why are you on tinder?"

Gemma reported that she initially used the app in hopes of procuring a romantic relationship or even platonic friendship, yet cultural expectations regarding how young, "independent" women are expected to behave integrally shaped her motivations for using Tinder, as Gemma wanted to avoid being thought of as "weak." This gender belief is reflective of what researchers call the self-development imperative (Hamilton and Armstrong 2009; Rosenfeld 2007). According to this imperative, young middle-class 
women are expected to delay committed relationships, which siphon time and energy from their investment in human capital, in favor of more strategic approaches to sex and relationships (2009: 594). While Hamilton and Armstrong (2009) argue that the selfdevelopment imperative is predominantly reflected by white, middle class cultural values, and is not typically shared by women from less privileged backgrounds (Hamilton and Armstrong 2009), findings from my interviews show that Tinder may be alleviating the raced and classed requirements of the self-development imperative. In fact, regardless of racial or class backgrounds, nearly all participants acknowledged that young adulthood was a period in their life where they should be focusing on the self and among those who engaged in hookups, racial and class locations varied considerably.

Provided that the hybrid hookup script was an accessible script for participants from diverse backgrounds, young women often regulated their behaviors to align with the social and cultural expectations associated with Tinder and young adult dating. Jade (white/working class), explained this process stating,

So I am not just looking to fuck. I don't want meaningless sex, I want dates and a connection and all of that cheesy stuff. But I've learned that this is either not what people want or that is not what people want me to want. I don't know, it's so easy to just fuck and if I'm told that's what 20 something year old guys want to do, then the chances of me meeting someone to date are really low. So I've kind of just accepted that that's how it is.

Jade's narrative reflects a relational double bind in which young women experience a tension between the desire for committed relationships and the cultural expectation to prioritize development strategies (Hamilton and Armstrong 2009: 604). For Jade, who 
comes from a white working-class background, establishing a relationship was the ideal outcome of using Tinder, yet the script that young men on Tinder only want casual sex became an internalized process of regulation, in which Jade policed her own desires to align with hybrid hookup script. Not only do contemporary sexual scripts communicate to young women that they should avoid committed relationships that may derail their ambitions, but the perception that hooking up is the norm on Tinder simultaneously encouraged women to engage in Tinder hookups. Moreover, because of the sexual expectations associated with the hybrid hookup script, women acknowledged that they learned to have low expectations of forming a relationship on the app. As a result, women on Tinder face compounding external pressures that guide their decisions to engage in the hybrid hookup script. As Lucia (Latina, upper class) described,

I've never felt pressured from any dude. I do think that because it is labeled as a hookup app, sex is in the back of everyone's mind. So there's usually the assumption that this could lead to something else. I just feel like it just gets physical so quickly for me on these kind of Tinder dates. It feels like there's this consensus that you're swiping on somebody because you want to fuck them, everybody knows that, so you go into the date with that knowledge.

Not only did Lucia suggest that all Tinder users share a set of norms and expectations regarding hooking up on Tinder, but she also described how the act of swiping right translates into a direct indication of sexual interest. Thus for Lucia, matching with a guy on Tinder implies that both parties are interested in a potential hookup. Given the perception of this shared knowledge, Lucia identified how the presumption of a hookup influenced her to move more quickly into sexual behaviors. 
In this way, participants struggled to negotiate between their internal desire for more committed relationships and the external expectation of a hookup. Although for a few women, the presumption of sex alleviated the guessing game associated with "dating in real life," for most, the norms associated with the hybrid hookup script nudged women into engaging in hookups. When asked about her experiences hooking up on Tinder, Em (white) explained how her hookups have not always been the desired outcome of a Tinder date.

I mean, I've probably slept with a lot of people on Tinder that I shouldn't have had sex with, but it's so convenient. I also don't like the idea these guys already have of me when I go into the date. Like, because of the reputation of Tinder, they think they're gonna hookup with you and you go on the date and you end up hooking up with them, like what are they supposed to think of you after that? I just think there's an expectation there, and I'd like to think it doesn't influence the way that I act, but what do I do over and over again? I hookup and I don't do that shit when I delete the app.

Compared to offline dating, Em, who came from a middle-class background, engaged in far more hookups with her Tinder partners, and although she was aware of the external pressures guiding her behavior, she reported that she continued to use Tinder out of the convenience of the app. Similarly, Ana (Latina/working class) recounted a particular Tinder date where she engaged in an unwanted hookup. According to her recollection, Ana had started talking to a boy on Tinder who eventually asked if she wanted to hang out that same day. Knowing that she did not want to hook up with him, she explicitly expressed her boundaries through a message on the app, but as she stated in the 
interview, "it’s Tinder, I knew what he expected." After going to the movies Ana

described how the formal date eventually turned into a casual hookup,

The next thing I know we were making out. I don't even know why I did it. But making out isn't the problem. It's just that I did end up going down on him and internally I was like, 'why am I doing this, I don't even know you?' Afterwards I just felt super gross. Like why did I do that? He definitely didn't take advantage of me or force me to do anything... but when I was there, it just felt like whatever, it's a Tinder date.

Ana explicitly stated that she was not looking to hookup with her match, yet eventually gave in to an external pressure to engage in a hookup. Thus, while Ana's desires align with research that indicates the young working-class women are more likely to prioritize committed relationships, her decision to perform oral sex on her Tinder match on account that "it's a Tinder date" underscores how the hybrid hookup script may be deconstructing the raced and classed boundaries of the traditional hookup culture. Further, although women reported using the Tinder profile to explicitly set and communicate their sexual boundaries, the hybrid hookup script has become so pervasive that men on the app often maintained the assumption of a hookup regardless. After going on a Tinder date with a match who was aware of her sexual boundaries, Isabella (white/working class) explained how he still maintained the presumption of sex,

"He said he wouldn't have gone through all the work to set up a date if he knew we weren't going to have sex, and I was very upfront that I didn't want to hookup or anything, like he said he still wanted to hang out, so I don't know. He was wanting to hang out that day, and I told him I couldn't because I knew he wanted to hookup, but he said it was fine if we didn't, and that we could still go out and eat or something. So I said I was down, it sounded fun. But then he still thought we were going to [hookup]." 
Rosa (white/middle class) describes a similar interaction,

"Sometimes I feel like there really is an expectation there that I am trying to fuck, or sometimes because I am that person who just wants to go get coffee, I find that they only want to meet later in the day... There are these guys who will be like, "want to have sex tonight? And when I say no, they will just be like "what the fuck are you doing here then? Why would you match with me if you don't want to have sex with me?" But I thought maybe we could sit down and have like an actual conversation about life..."

Although both Rosa and Isabella were aware of the sexual expectations associated with the app and explicitly communicated their sexual boundaries to matches, both experienced backlash against their decision not to enact the hybrid hookup script. While Isabella's Tinder match shamed her for making him set up a Tinder date without giving in to the expectation of a hookup, Rosa's match refused to even meet with her unless a hookup was on the table. As a result, several participants revealed that when they tried to communicate their boundaries to a match, men would often "ghost" them. "Ghosting" occurs when a match unexpectedly stops communicating without any explanation.

Regardless of whether or not participants engaged in a hookup, nearly all participants reported at least one experience of being ghosted by a match on Tinder. This process often involves matches removing a person from all social media accounts and blocking them on Tinder. For a number of women, men ghosted immediately after a hookup, and for others after refusing to participate in a hookup. Ghosting was such a consistent aspect in the narratives of young women that many began to accept and recognize it as "part of the process." For instance, Charlotte (white) explained, 
I always take it personally after having slept with someone and then never hearing back from them. Then, when I've been consoled by my peers, they're just like, 'Well, that's Tinder, it's a hookup.' So there's very much this idea of, 'Well, what did you expect?' And that really sucks, but this is it, this is how it is. I want so much more, but then I think, that's just how things work now.

Charlotte's experience with ghosting was normalized through her interactions with friends, who communicated to Charlotte the norms associated with the hybrid hookup script. Notably, ghosting was not a one-sided behavior. While women espoused a general frustration with men who ghost on the app, they also admitted to ghosting their matches as well. According to Lucia (Latina)

I feel like these apps are giving both parties a reason to ghost people and just not respond and not give a reason why you're not into it and I hate that. It's my biggest pet peeve, because it's so disrespectful to just never talk to someone again that you just hooked up with. That's a super intimate thing and to just not reply just sucks. And then, if you're aggressive about it and hit them up asking what happened, they think you're crazy or overbearing, because the norm is to just not reply. And I've done it too and I'm just as guilty... It's easier to do that than to have the conversation and that's not how it should be. Tinder is just the easy way in and ghosting is the easy way out. Just because it's good doesn't make it right.

Even though ghosting was one of Lucia's biggest pet peeves surrounding Tinder, she still engaged in the act, justifying her behavior by acknowledging the ease and normalcy of ghosting Tinder matches. Again, we see how the Tinder platform shapes the sexual scripts of young adult dating, as women and feminine Tinder users normalize and accept ghosting as an expected conclusion to the hybrid hookup script.

The Hybrid Hookup Cycle 
Regardless of participant's frustrations with the outcomes of their Tinder dates, women continued to use the app out of a perceived lack of other options to meet men. While other casual dating apps have grown in popularity, such as Bumble which provides a user interface that is propagated as 'female friendly,' because women must make the first move; participants' insistence on men initiating conversations coupled with their desire to avoid looking "desperate" for a relationship, confined them to Tinder.

Therefore, according to participants, Tinder was viewed as the primary means to meet potential romantic and/or sexual partners today. When reflecting on why she continues to use Tinder, Em (white) explained,

Tinder is so bad, because it's not like funny bad or painful bad, it's just been like shit. Is this how people date now? It's so mediocre. Like I have gone out with a lot of guys and we've had a beer and then they finger fuck me really badly, then we smoke weed and then I never see them again. It's like why do I do that? Then I do it two days later. But what else am I going to do?

As Em described her experiences on Tinder, she invoked the idea that Tinder was her only option and although she wasn't happy with her experiences, she was caught in a cycle of enacting the hybrid hookup script. In fact, for many women, Tinder has been a consistent platform for their dating and hookup practices, as Isabella recalled, "My only dating experiences have been filtered for through Tinder." Similarly, Gemma exclaimed, "I don't know where I would be without it!" Given that Tinder has become increasingly popular since 2012, several participants had never experienced dating and hooking up outside of mobile apps and echoed a similar dependence on Tinder for meeting potential 
partners. For some, the accessibility of the hybrid hookup script enabled women to solely rely on the app to meet men. For example, Lauren explained how she depends on Tinder,

It seems rare to meet a guy in person these days, like it's so much easier to meet a guy online and to just talk to them online. I would never approach a guy at a bar... I have no pick-up lines because I don't meet people in real life. Instead, I'll just get on Tinder, turn my location radius down to 1 mile to see if I can swipe until I find him.

The convenience of the Tinder app is heavily cited as a justification for this reliance on technology to meet potential partners. In this way, the hybrid hookup script becomes a pervasive aspect of young adult dating. As a result, participants indicated a general assumption that if you are a young single adult, you have a Tinder. Regardless of whether women were satisfied with their experiences on the app or not, the accessibility of Tinder created an environment that felt "inescapable" (Fatima) for many participants. This was reflected by participants cyclically deleting and re-downloading the app every several weeks or months. Carly (white) explained this cycle when she reflected on her overall experience with the app,

I don't hate it I actually love it. Its instant gratification, which I admit to loving. But it also reinforces everything we are trying to combat as women. I have problems with relationships because I've grown up since I was 12 years old having some kind of online presence... and that's not what I want, so I delete it. But then I try dating in the real world for like 4 or 5 weeks, and that's not working-I want instant gratification, so I go back. 
Carly's experience points to a tension between enjoying the ease of the app and a general dissatisfaction with Tinder outcomes. While the instant gratification of the app keeps women (re)downloading Tinder, the process of maintaining a Tinder profile and sorting through an endless deck of potential matches eventually becomes exhaustive for women. According to Elena (white), "I can’t really stress enough how damaging it can be though. I put so much effort into taking the perfect photo and showing off my body and my looks because it was being received so well, but it just ended up feeling like this sick cycle." For Elena, the visibility of the app, while proving her with a quick "ego boost," became a cyclical process as she struggled to negotiate a balance between a sense of control and objectification. Isabella (white) additionally felt this dissatisfaction,

The only way I can sum it up is like you have to weigh the power dynamics. It's great that I can meet a guy and fuck him and sometimes its good sex and sometimes they call you back, and I know its suppose to feel empowering... but I refuse to believe power comes from whether or not a guy on Tinder thinks I'm fuckable. Let's get real, that's misguided power. Because whatever way you slice it, men come out on top.

Although cultural scripts encourage young women to enact the hybrid hookup script, women continue to face a sexual double standard as men retain greater control over the terms of hooking up. Thus, participants regard the app as a "man's game" (Em) and often disclose that they hope that they will eventually "get off Tinder for good" (Aleia). When asked if they would recommend using Tinder to a friend, 21 out of 25 participants reported that they would warn them otherwise. In fact, at the time of the interviews, 11 participants indicated that they had deleted their Tinder profile. Among these women, 7 identified as women color. In the following section, I examine the narratives of those who 
chose to opt out of behaviorally enacting the hybrid hookup culture, underscoring how interactions on Tinder operate to maintain hierarchies of gender and race. 


\section{Chapter 6}

\section{Gender, Race, and Opting Out}

All participants expressed a clear familiarity with the hybrid hookup culture and the sexual expectations associated with Tinder. However, not all participants enacted the hybrid hookup script equally. Notably, women of color were overrepresented among those who explicitly rejected the hybrid hookup script or eventually chose to opt out of the hybrid hookup culture altogether. Although recent literature on the hookup culture has examined how college sexuality is impacted by multiple intersecting structures (Hamilton and Armstrong 2009; Allison and Risman 2014), there remains a dearth of empirical work examining how compounding social identities shape young adults' experiences with dating and hooking up through dating apps. Considering the design features of Tinder which allow users to select potential hookup partners based primarily on profile photos, it is necessary to understand how the intersection of gender and race operate to inform young women's enactment of the hybrid hookup script. In this section, I examine how the "whiteness" of Tinder in Portland, Oregon establishes a platform at odds with minority participants' desire to seek potential partners with similar racial/ethnic backgrounds. In addition, while I cannot be certain that women of color experience more sexual harassment on the app, findings from my interviews show how women of color were more aware of their experiences with harassment and were subsequently more likely to delete the app than their white counterparts. As a result, women of color experience increased social barriers to participating in the hybrid hook up culture, unveiling the gendered and racialized nature of the hybrid hookup script. 


\section{Racial Homophily and the "Whiteness" of Tinder}

Supporting an established body of literature that indicates that online daters prefer partners who share their racial identity (Robnett and Feliciano 2011; Rosenfeld and Thomas 2012: Lin and Lundquist 2013), findings from my analysis reveal that a desire for same-race sexual/romantic relationships puts young minority women at a distinct disadvantage in the hybrid hookup culture by limiting the pool of potential matches (Allison and Risman 2014). Because Tinder locates potential matches based on geographic proximity, the racial and ethnic demographics of Tinder are likely skewed by the overwhelmingly white composition of the Portland metro area. In fact, when reflecting on her experiences with dating on Tinder, Kaelyn (Black), who recently moved from Chicago, Illinois to Portland, Oregon, described how she eventually stopped using Tinder out of a lack of prospective partners,

I think because it's been such a disappointment here, I just stopped using it and reverted to meeting people in real life... It's just different because in Chicago people are different, its just more diverse. Personally, I've never dated a white guy or had sex with a white guy, so my Tinder is just a lot of white people, and it's like 'oh my god how am I going to do this?'... You get on Tinder and it's like white people are my only option. It's mind blowing

Kaelyn went on to explain that when she was living in Chicago, finding men to match with on Tinder was not difficult, she described that she often went on multiple dates a week and did not anticipate that anything would change after relocating. However, because Tinder operates as a location based dating app, geographic proximity plays a central role in organizing the deck of men to choose from. Thus, given the disproportionality white demographics of the Portland metro area, participants of color 
struggled to find same-race peers to match with. Mikayla (Asian American) had a similar response to Kaelyn when she explained whom she was looking to match with,

There's more attractive people in New York than Portland to me... I didn't realize it until I would look through my matches and I primarily swipe on Asian guys... I've dated white guys and I think culturally we don't match up. I think its because my culture is very different from what they're [white men] used to. The traditions, like take your shoes off when you enter the house and greeting everyone with a specific title, they just don't understand... There are just too many cultural differences where I don't feel connected to them. Like at least Asian guys, they have a sense of the same culture.

For Mikayla, finding a potential match that understood her background eased the process of meeting men offline. She recalled that dating Asian men alleviated the extra work of explaining her culture to a potential partner. Although Mikayla had specific goals in mind when looking for a potential match, she struggled to find same-race partners on Tinder. When she did match with white men, the messages she received had fetishizing undertones.

There are not many of us [Asian Americans] either. If you look at Tinder, 90 percent of the people on there are white. And if they're not Asian, they'll usually say something about my ethnicity or my culture. They'll be like, 'Oh man that's so cool' and really into it and it really weirds me out. Like its cool to appreciate ones culture but I've had so many instances where it just comes off as a little fishy.

Eventually Mikayla explained that she gave up on Tinder. Not only could she not find a match with a similar racial background, but messages from white men regarding her ethnicity and culture were perceived as a form of eroticization by men who wanted to "try me [her] out." Mikayla was not the only participant to explicitly acknowledge the 
issue of white men fetishizing women of color on the app. Several participants revealed that sexually harassing messages eventually deterred them from enacting the hybrid hookup script.

Perception of Harassment and Racist Sexual Scripts

While nearly all participants mentioned instances of experiencing sexual harassment on Tinder, perceptions of sexual harassment varied by racial/ethnic identity. When reflecting on instances of harassment, white women were quick to shrug off harassing messages and photos as a normalized aspect of Tinder, as Charlotte (white) notes, "Guys just say things that they would never say in person... but it doesn't really bother me, it's just bubbles on a screen." On the other hand, women of color were hyperaware of their experiences of sexual harassment and describe how unsolicited messages from white men were both sexually and racially charged. Initially, when asked about their experiences dealing with sexual harassment on Tinder, a number of white participants did not immediately recognize their interactions with men to be particularly sexually aggressive or hostile. Yet, as the interview continued and participants reflected on their online interactions, women began to remember multiple instances in which men sent unwanted and nonconsensual messages and photos. For instance, when asked about how she handles harassment Amy (white) explained,

I don't really... yah I have had a few times where people have been lewd and made lewd comments and maybe I'm cocky because I think I handle it really well, because I just take a screen shot of it and throw it up on my Instagram in a funny tongue in cheek way. But I can honestly say that has only happened a couple... well like 4 or 6 times. I guess that's still not okay. Okay wow, that's terrible. 
Amy did not initially recognize her experiences to be instances of sexual harassment. However, as Amy continued to think about her interactions on Tinder, she continued to detail numerous harassing messages from men on the app. This was not unusual for participants. Due to the design features of Tinder, which enables users to communicate through messages rather than face-to-face contact, white women did not take sexual harassment to be particularly threatening. By and large, women reported that the ability to block matches or report users for sexual harassment provided a sense of security. Although most women either deleted or block matches who sent them inappropriate content, several participants described how they would play along by responding with similarly suggestive messages and then ghost once they were tired of the conversation. Compared to white participants, women of color were more aware of their experiences of sexual harassment on Tinder. This finding shows support for a body of work that finds that young women of color are more conscious and sensitive to racial stereotypes then their white peers (Ryan et al. 1996; Stephens and Phillips 2005). While nearly all participants, regardless of racial/ethnic identity received sexually explicit messages and photos from men on Tinder, women of color often struggled to disentangle their experiences of sexual harassment from racial harassment. When asked how their racial/ethnic identity may influence their experiences on Tinder a number of women of color recognized that varying cultural stereotypes and scripts shape how men interacted with them on the app.

I feel like being Latina made things different... You know, the way social media has portrayed Latinas sexualized how I might present myself. I feel like when 
they see my profile, guys are like "oh she's from this ethnic background, like she's probably easier to get at" (Ana, Latina)

I have often thought about that, because the "Wanna fuck?" thing is usually from white guys and I am not sure, maybe they do that to all women but if feels like they see me as some kind of Jezebel, ya know, like I'm easy to sleep with. (Aleia, Black/Native American)

Both Ana and Aleia expressed concerns over being hyper-sexualized due to their racial and ethnic identities. In fact, when examining the messages she received from white men, Aleia explicitly draws on the historical construction of the Jezebel. According to Collins (2000), the Jezebel was an image imposed on African American women by the white ruling class as a process of dehumanization; depicting racialized women as sexually insatiable and relentlessly promiscuous. The remnants of these images continue to be rearticulated and disseminated throughout contemporary media portrayals of Black women as hypersexual and sexually aggressive (Stephens and Few 2005). In this way, gendered and racialized scripts shape how others may view and interact with young Black women (Stephens and Phillips 2005: 39). In fact, throughout my interviews with women of color, particularly Black women, participants described the impact of such controlling images, as Kaelyn (Black) explained, "people are like rude and will send me a message and ask me for a blow job, this happens actually quite often, and I'm like 'I'm not an escort, I'm just a person on Tinder."” Additionally, when asked about her experiences on Tinder, Deja (Black) noted,

A lot of people that I end up talking to eventually end up admitting that they just like 'big black women' and so, I think that they just perceive me as a black girl 
and they don't see much otherwise. If that's what they're into they will try and talk to me pretty quick after we match. I think I'm seriously just seen as big and black and that's it. So a lot of guys will ease into it and be like, 'yah, I'm into this and that,' and then they'll be like "I'm really into big black butts" or "I'm into big girls" or "black girls." Then it's obviously that that is the only reason they are talking to me, because I fit into that category. And it's honestly only white men. I feel like they're naïve about it. They see me as a new experience and that's fucked up. Most black men don't talk to me that way.

Messages from white men looking for "big black women" or propositioning women for sex were perceived by women as illustrations of explicit objectification. In response, Deja describes going back through her photos and uploading new, more conservative pictures to her Tinder profile. In a moment of internalization, Deja considered that her photos were sending men the wrong message. However, this did not detour white men from continuing to sexually harass Deja through the app. Shortly after Deja changed her profile, she received a message that read: "You're like an Oreo. I want to spread you apart and lick the cream inside of you." Explaining how this made her feel, Deja stated,

It made me uncomfortable, really uncomfortable. I do not like them, because I didn't ask for it. Like I specifically stated in my bio after the first day of having Tinder that I was only looking for friends because you kind of have to... I should've done it sooner. I didn't even get to a date before I realized how bad it was... But I feel restricted to Tinder, which sucks because I don't think I'll go back. Only because I'm afraid that if I meet the wrong person I can get hurt...Coming at me like all I am is this big fat black ass is pretty violent to me, it's like a slap in the face.. it makes me feel insecure and I just don't want to use it. 
Although Deja recognized that Tinder was her main resource for meeting potential partners, the harassment from white men was enough for Deja to remove herself from Tinder altogether.

Notably, this fear was a sentiment echoed by several women of color. While a number of white participants confronted sexual harassment head on by responding to harassing messages directly or by playing along with men and then ghosting, women of color had to carefully navigate their interactions with sexually aggressive men on Tinder out of fear of potential retaliation. For some, responding to sexually explicit comments could end up encouraging further harassment, as Ana (Latina) indicated,

Latinas are known to be really angry, or characterized as angry or fiery, so a response could definitely backfire. Because if I respond, which I usually never respond, there's usually a lot of backlash tied into that. So if I talk back to someone who is trying to sexualize me on Tinder, then they'll just be like, 'oh she's Latina and that's why she's responding like that.' There's a lot of things tied into it, whereas if anybody else would talk back it might be more received, 'like oh ya, you shouldn't be talking to them like that,' but with Latinas, they think its okay, like we're used to it or we like it. But no, were not used to it. We don't want it and we don't like it.

Beyond risking physical and emotional harm, Ana was pressed against a reluctance to feed into the Latina stereotype that men were expecting. Again, Ana's narrative points to the power that contemporary controlling images have to communicate to others how Latina women are expected to behave. For Ana, the stereotypical sexual script of the "Fiery Latina" confined her ability to push back against men who harassed her on Tinder. In one instance, however, when Ana decided to respond to a man repeatedly messaging 
her on Tinder, her match replied: "No Mexicans on my level anyways." After this encounter, Ana stopped responding and eventually deleted the app. Beyond the threat of racist responses and comments from white men on Tinder, women of color also feared that addressing sexual harassment through the app could put them in a physically dangerous situation. When asked about how they handled harassment on Tinder, Carly who identifies as a non-binary, femme Arab American explained that because of their intersecting gender and racial identities, they must be extremely cognizant of not only who they match with, but how they interact with men on Tinder. Particularly, Carly explained how they perceived of the control white men maintained on Tinder, "These cis hetero white men on Tinder are entitled to basically everything and rarely are they physically or verbally chastised for it. And when they are they can usually push back harder:" When asked whether or not they ever 'pushed back' against sexual harassment from white men, they explained,

It depends, a big part of me at all time wants to face harassment head on, with like a big fuck you and a middle finger. But honestly I can't do that most of the time, because there's such a chance that I'll get hurt badly if I do that, or something bad will happen.

Not only does Carly have to be cautious when responding to white men on Tinder because of their race, but also because they do not adhere to the hegemonic gender binary that Tinder relegates them too, they are simultaneously hyperaware of how cis hetero men may react to their gender identity. Thus, for women of color, Tinder is often perceived as a hostile environment for the establishment of sexual/romantic relations. 
Due to the oversaturation of white male users in the Portland metro area, women of color who seek same-race peers may be at a disadvantage in the mobile dating market. Further, among those who swipe right on white men, sexually aggressive and fetishizing comments that draw on historically racist images of women of color communicate to participants the hyper-sexualized and racialized expectations of their matches. 


\section{Chapter 7}

\section{Conclusion}

While a growing body of literature exists examining how intersecting social identities and structural organizations shape the on-campus hookup script (Bogle 2008; Heldman and Wade 2010; Reid et al. 2011; Armstrong and Hamilton 2013; Berntson et al. 2013; Allison and Risman 2014), research examining the impact of technology on the hookup culture has been virtually nonexistent (for an exception, see Goluboff 2015). Addressing this gap, this study adds to a current body of literature on the hookup culture and online dating by exploring how a diverse sample of young women and non-binary, femme individuals understand and negotiate interpersonal sexual scripts through the mobile dating app Tinder. Ultimately, findings from 25 in-depth interviews reveal how Tinder has shaped the sexual scripts of young adult dating into a "hybrid hookup script." Unlike the traditional college hookup culture, which centers the hookup script on fraternity parties, sexual dancing, and drinking, the hybrid hookup script reintroduces traditional dating practices, such as formal dates, into the modern sexual scripts of young adults. Specifically, the hybrid hookup script maintains the traditional gendered expectation that men initiate conversations and dates, while incorporating the patterns of drinking and the expectation of non-relational sex central to the on-campus hookup culture. According to participants, women learned the rules of the hybrid hookup script through friends and matches who communicate to participants that Tinder is meant for hookups. 
Regardless of the motivations participants reported for downloading the app, the perception that hooking up is the norm on Tinder pressured young women into adhering to the hybrid hookup script. This finding is consistent with previous research that shows that young women may overestimate the frequency in which their friends hookup and are subsequently more likely to engage in hookups in order to fit in with the image that they have of their peers (Heldman and Wade 2010; Berntson et al. 2014). Similarly, feminine Tinder users indicated that because hooking up was a presumed aspect of a Tinder date, they were more likely to engage in sexual activities with their matches. Women did not find this unproblematic. Not only were participants frustrated with the sexual expectations and the stigma associated with meeting men off the app, but they also complained of feeling disrespected by matches who would "ghost" after a Tinder date or hookup.

Thus, interviews unveil the gendered implications of the hybrid hookup script. According to participants, the rules associated with the modern script maintain a sexual marketplace run by men, as Jade exclaimed "what a time to have a dick!" In fact, participants reveal a tension between an increased sense of control over their ability to choose a match, and a dissatisfaction with the control men retained over the terms of their mobile interactions. Because men are the primary initiators of conversations, Tinder dates, and Tinder hookups, women report a reduced sense of agency over their relationships and hookups established online. Notably, while most participants explicitly indicated that they were disappointed with the outcome of their Tinder dates, other suggested that they may have been more interested in Tinder hookups had they not been 
faced with a Tinderslut. It is therefore likely that this sexual double standard further constrained women's ability to enjoy their hookups and Tinder dates. Thus, while participants expressed a general dissatisfaction with the app; for participants living outside of the on-campus hookup culture, Tinder was perceived as one of the only pathways for young adults to form romantic and sexual relationships. Not only is this pathway convenient because it mediates the risk involved in indicating a sexual/romantic interest, but for many young women the hybrid hookup script is also the only script with which they have experience. As a result, participants were often caught between a desire to delete the app in hopes of meeting someone "organically" and the idea that the only way to meet someone in today's culture is through Tinder. Therefore, for young women, the hybrid hookup script has becomes a pervasive aspect for young adult dating. Additionally, my findings highlight how women and non-binary, femme participants between 18 and 26 years of age understand and use the app differently than adult users. Although research shows that heterosexual adults between the ages of 26 and 36 use Tinder in search of love and/or committed relationships, reflective of traditional online dating practices (Hobbs et al 2016; Ranzini and Lutz 2016), the young women I interviewed associated the app with hookup culture and subsequently formed more casual and informal relationships. According to Allison and Risman (2014), "the developmental tasks of young adulthood, including negotiations between autonomy and peer conformity, the development of interpersonal relationships and sexual identity formation, support the hookup culture" (p. 57). Therefore, age is a prominent mechanism behind alternative sexual scripts. For young women and non-binary, femme individuals on Tinder, the 
hybrid hookup script matches the social expectation that young adults should postpone romantic relationships in favor of less distracting hookups and casual encounters.

Although, Hamilton and Armstrong (2009) have argued that these cultural expectations are class-specific, my findings show that the developmental imperative may be transgressing racial and class boundaries as nearly all of the participants in my sample, regardless of their social locations, acknowledged that they were at a time in their life where they should be prioritizing themselves over their relationships. In this way, my interviews support Alison and Risman's (2014) finding that students of color and students from lower-socioeconomic backgrounds do not explicitly reject hooking up as a dominant sexual script but experience structural barriers to enact hooking up as frequently as their white middle class peers (p. 119). Therefore, while Tinder has been successful in exporting the hookup culture beyond the boundary of residential college campuses, women of color continue to experience social barriers to enacting the hybrid hookup script.

Nearly all participants engaged in the hybrid hookup script to some extent; yet, women of color were overrepresented among those who eventually opted out of Tinder altogether. Congruent with a substantial body of literature documenting how racial stratification manifests through online dating websites and within an on-campus hookup culture (Robnett and Feliciano 2011; Rosenfeld and Thomas 2012: Lin and Lundquist 2013; Allison and Risman 2014; Berntson et al. 2014), most women of color reported that the hybrid hookup script was at odds with their desired outcomes of Tinder. Notably, women of color did not reject the hookup script but the environment established by 
Tinder did not align with their desire to access same-race peers. Because Tinder locates matches based on geographic proximity, the predominantly white demographics of Portland Oregon made it increasingly difficult for women of color to match with potential partners from similar racial or ethnic backgrounds. Further, when women of color did match with white men, experiences of sexual and racial harassment created an environment in which women of color felt racially objectified and fetishized. While it is worth noting that the majority of my participants reported multiple instances of sexual harassment, white women were more likely to disregard these instances.

According to more privileged participants, the ability to ignore or block men who sent sexually explicit or aggressive messages made experiences of sexual harassment easier to ignore. In line was literature that shows that women of color are more aware and sensitive to instances of racial stereotyping than their white peers (Ryan et al. 1996; Stephens and Phillips 2005), my participants of color were far more aware of their experiences of sexual harassment on the app. Because the messages sent by white men to women of color were not only sexually explicit but were also drawn from historically racist images and scripts that hypersexualized Black and Latina women, participants of color faced compounding forms of racial and sexual harassment. Therefore, while I cannot determine whether or not women of color faced more harassment than white participants, my results do indicate that navigating the racism and sexism embedded in the hybrid hookup script became an exhaustive process for women color. Eventually, most of the women of color interviewed indicated that they deleted the app for good. This finding may not be news to Tinder. In February of 2018, Tinder launched a campaign 
called \#Representlove advocating the development of an interracial couple emoji. According to the campaign page, "At Tinder, we believe that no one should ever feel unrepresented or unseen. Love is universal, and it's time for interracial couples to be represented in our universal language." Perhaps, Tinder's own campaign can help to advance alternative scripts for interracial couples and racially diverse Tinder users, however future research is necessary in order to fully understand the diversity of experiences of Tinder users.

While this study aims to lay a foundation for understanding the convergence of mobile media and the development of young adult sexuality, it is not without its limitations. Due to constraints on time and funding resources, this project utilizes nonrandom sampling in order to access a small sample size of self-identified women and non-binary, femme Tinder users, thereby restricting my ability to draw conclusions about gender differences and limiting the overall generalizability of my findings. Future research on the experiences of men on Tinder is necessary to fully round out our understanding of the hybrid hookup script. Further, while my sample is racially and sexually diverse, my decision to focus on participants experiences with interacting with men on the app ignores the experience of my queer participants who also swipe for women or 'both,' adding to an established body of literature that takes a heteronormative approach to studying sex and sexuality. My next step would be to explore the sexual scripts of queer identified participants. Also, I want to be careful not to homogenize the experiences of women from diverse racial and ethnic backgrounds. Within my small sample I draw conclusions about women of color generally, however women from 
different racial backgrounds experience unique instances of marginalization. Given a larger sample size, researchers should continue to explore the diversity of experiences of Tinder users to continue to examine how intersectional identities and social locations shape the sexual scripts of Tinder users. Finally, to study new media is to study a moving target. Throughout the duration of my research, the design features of Tinder evolved. For instance, midway through my recruitment process, Tinder added a group dating feature, which was subsequently addressed in some of my later interviews. Future research should employ comparative or longitudinal methods to study participants over time and across dating platforms in order to address the constant development of digital dating and provide further insight into the conditions under which the hybrid hookup script is understood and enacted.

Overall, the results of this study bear important implications for examining the development of interpersonal sexual scripts in the digital age. As dating apps such as Tinder become increasingly popular among young adults, researchers can no longer examine the evolution of modern sexual and gendered scripts separately from the technologies in which they are constructed and enacted (Goluboff 2015: 118). Therefore, by shifting the focus on hook ups from the residential college campus to the Tinder platform, this study contributes to Simon and Gagnon's (1986) sexual script theory by furthering our understanding of the ways in which technology has shaped the sexual "scriptwriting" processes of a diverse sample of young women and non-binary, femme Tinder users. 


\section{References}

Allison, Rachel, and Barbara Risman. 2014. "It Goes Hand in Hand with the Parties": Race, Class, and Residence in College Student Negotiations of Hooking Up." Sociological Perspective 57(1): 102-123.

Armstrong, Elizabeth and Laura Hamilton. 2013. Paying for the Party: How College Maintains Inequality. Cambridge, MA: Harvard University Press.

Bartoli, Angela, and Diane Clark. 2006. "The Dating Game: Similarities and Differences in Dating Scripts Among College Students." Sexuality and Culture 10(4): 54-80.

Barraket, Jo, and Millsom Henry-Waring. (2008). "Getting it On(line): Sociological Perspectives on E-Dating.” Journal of Sociology 44(2): 149-165.

Barriger, M., and Velez-Blasini, C.J. 2013. "Descriptive and Injunctive Social Norm Overestimation in Hooking Up and their Role as Predictors of Hook-up Activity in a College Student Sample." Journal of Sex Research 50: 84-94.

Bay-Cheng, L., Robinson, A. D., \& Zucker, A. N. 2009. "Behavioral and relational contexts of adolescent desire, wanting, and pleasure: Undergraduate women's retrospective accounts." Journal of Sex Research 46: 511-524.

Ben-Ze've, A. 2004. Love Online: Emotions on the Internet. Cambridge: Cambridge University Press.

Berntson, Marit, Kristi Hoffman, and Tracy Luff. 2014. "College as Context: Influences on Interpersonal Sexual Scripts.” Sexuality \& Culture 18: 149-165.

Bogle, Kathleen. 2008. Hooking Up: Sex, Dating, and Relationships on Campus. New York: New York University Press.

David, Gaby, and Carolina Cambre. 2016. "Screened Intimacies: Tinder and the Swipe Logic.” Social Media \& Society 2(2): 1-11.

Davis, M., Hart, G., Bolding, G., Sherr, L., \& Elford, J. (2006). "E-dating, Identity, and HIV Prevention: Theorizing Sexualities, Risk, and Network Society." Sociology of Health and Illness 28(4): 457-478.

England, Paula, Elizabeth Armstrong, and Alison Fogarty. 2012. "Accounting for Women's Orgasm and Sexual Enjoyment in College Hookups and Relationships." American Sociological Review 77(3): 435-462.

England, Paula, Emily Fitzgibbons Safer, and Alison Fogarty. 2007. Hooking Up and Forming Romantic relationships on Today's College Campuses. In The Gendered Society Reader, $3^{\text {rd }}$ edition, edited by Michael S. Kimmel and Amy Aronson. New York: Oxford University Press.

Fullilove, M. T., Fullilove, R. E., Hayes, K., and Gross, S. 1993. "Black Women and AIDS Prevention: a View Towards Understanding the Gender Rules. In M. Berer (Ed.), Women and HIV/AIDS: An International Resource Book. London: Pandora.

Grigoriadis, V. 2014. "Inside the Hookup Factory." Rolling Stone Magazine. Retrieved from http://www.rollingstone.com/culure/features/inside-tinders-hookup-factory20141027

Goluboff, Sascha. 2015. "Text to Sex: The Impact of Cell Phones on Hooking Up and Sexuality on Campus." Mobile Media \& Communication 4(1): 102-120.

Hardey, Mariann. 2002. "Life Beyond the Screen: Embodiment and Identity through the Internet.” The Sociological Review 50(4): 570-580. 
Hardey, Mariann. 2008. "The Formation of Social Rules for Digital Interactions." Information, Communication, \& Society 11(8): 1111-1131.

Hamilton, Laura, and Elizabeth Armstrong. 2009. "Gendered Sexuality in Young Adulthood: Double Binds and Flawed Options.” Gender \& Society 23(5): 589616.

Heldman, C. and Wade, L. 2010. "Hook-up Culture: Setting a New Research Agenda." Sexuality Research and Social Policy 7: 323-333.

Higgins, Jenny, and Irene Browne. 2009. "Sexual Needs, Control, and Refusal: How "Doing" Class and Gender Influences Sexual Risk Taking." Journal of Sex and Research 45: 233-245.

Hobbs, Mitchell, Stephen Owen, and Livia Gerber. 2016. "Liquid Love? Dating Apps, Sex, Relationships and the Digital Transformation of Intimacy." Journal of Sociology, Advance Online Publication. doi: 10.1177/1440783316662718

Kreager, Derek, Shannon Cavanagh, John Yen, and Mo Yu. 2014. "'Where Have All the Good Men Gone?' Gendered Interactions in Online Dating.” Journal of Marriage and Family 76: 387-410.

Levy, G.D. 2000. "Individual Differences in Race Schematicity as Predictors of African American and White Children's Race-Relevant Memories and Peer Preferences." Journal of Genetic Psychology 161: 400-420.

Lin, Ken-Hou and Jennifer Lundquist. 2013. "Mate Selection in Cyberspace: The Intersection of Race, Gender, and Education." American Journal of Sociology 119(1): 183-215.

McWilliams, Summer and Anne Barrett. 2014. "Online Dating in Middle and Later Life: Gendered Expectations and Experiences.” Journal of Family Issues 35(3): 411436.

Madden, M., \& Lenhart, A. 2006. "Online Dating." Pew Research Internet Project.

Mason, Corinne. 2015. "Tinder and Humanitarian Hook-ups: The Erotics of Social Media Racism." Feminist Media Studies 16(5): 822-837.

McGrath, Alison, Glenn Tsunokai, Melinda Schultz, Jillian Kavanaugh, and Jake Tarrence. 2016. "Differing Shades of Colour: Online Dating Preferences of Biracial Individuals." Ethnic and Racial Studies 39(11): 1920-1942.

Oliver, Beth, and Janet Hyde. 1993. "Gender Differences in Sexuality: A MetaAnalysis." Psychological Bulletin 114(1): 21-51.

Reid, Julie, Sinikka Elliot, and Gretchen Webber. 2011. "Casual Hookups to Formal Dates: Refining the Boundaries of the Sexual Double Standard." Gender \& Society 25(5): 545-568.

Robnett, Belinda and Cynthia Feliciano. 2011. "Patterns of Racial-Ethnic Exclusion by Internet Daters.” Social Forces 89(3): 807-828.

Rosenfeld, Michael and Reuben Thomas. 2012. "Searching for a Mate: The Rise of the Internet as a Social Intermediary." American Sociological Review 77(4): 523-547.

Ryan, C.S., Park, B., and Judd, C.M. 1996. "Assessing Stereotype Accuracy: Implications for Understanding the Stereotyping Process.” In C.N. Macrae, C. Stangor and M. Hewstone (Eds.), Stereotypes and Stereotyping (pp. 121-157). New York: Guilford. 
Sakaluk, John, Leah Todd, Robin Milhausen, Nathan Lachowsky. 2014. "Dominant Heterosexual Scripts in Emerging Adulthood: Conceptualization and Measurement.” Journal of Sex Research 51(5): 516-531.

Smith, Aaron and Maeve Duggan. 2013. "Online Dating \& Relationships." Pew Research Internet Project.

Simon, William, and John Gagnon. 1986. "Sexual Scripts: Permanence and Change. Archives of Sexual Behavior 15(2): 97-120.

Sumter, Sindy, Laura Vandenbosch, and Loes Ligtenberg. 2017. "Love me Tinder: Untangling emerging adults' motivations for using the dating application Tinder." Telematics and Informatics 34: 67-78.

Stephens, Dionne, and Layli Phillips. 2003. "Freaks, Gold Diggers, Divas and Dykes: The Socio-historical Development of African American Female Adolescent Scripts. Sexuality and Culture 7: 4-47.

Stephens, Dionne, and Layli Phillips. 2005. "Integrating Black Feminist Thought into Conceptual Frameworks of African American Adolescent Women's Sexual Scripting Processes." Sexualities, Evolution, and Gender 7(1): 37-55.

Stephens, Dionne, and April Few. 2005. "The Effects of Images of African American Women in Hip Hop on Early Adolescents' Attitudes toward Physical Attractiveness and Interpersonal Relationships." Sex Roles 56(3): 251-264.

Sterk-Elifson, C. 1994. "Sexuality among African American women." Sexuality across the Life Course (pp. 99-126). Chicago: The University of Chicago Press.

Thomas, Davis. 2006. “A General Inductive Approach for Analyzing Qualitative Evaluation Data." American Journal of Evaluation 27(2): 237-246.

Tong, Stephanie, Jeffery Hancock, Richard Slatcher. 2016. "Online Dating System Design and Relational Decision Making: Choice, Algorithms, and Control." Personal Relationships 23: 645-662.

Van Acker, E. 2001. "Contradictory Possibilities of Cyberspace for Generating Romance." Australian Journal of Communication 28(3): 103-116.

Waxman, Olivia. 2016. "This is the 'Most Popular' Dating App in the World." Time Magazine, February 11. Retrieved April 5, 2018 (http://time.com/4217902/tinderdating-app-badoo/).

Wiederman, Michael. 2005. "The Gendered Nature of Sexual Scripts. Family Journal 13(4): 496- 502.

Wiederman, Michael. 2015. "Sexual Script Theory: Past, Present, and Future." Handbook of the Sociology of Sexualities. Springer International Publishing: Switzerland.

Windsor, Liliane, Eloise Dunlap, and Andrew Golub. 2010. "Challenging Controlling Images, Oppression, Poverty, and Other Structural Constraints: Survival Strategies Among African American Women in Distressed Household.” Journal of African American Studies 15(3): 290-306.

Wingood, G.M., DiClemente, R.J., Harrington, K., Davies, S., Hook, E. W., and Oh, K. 2001. "Exposure to X-rated Movies and Adolescents' Sexual and Contraceptiverelated attitudes and behaviors. Pediatrics 107: 1116-1120.

Wingood, G.M., DiClemente, R.J., Bernhardt, J.M., Harrington, K., Davies, S.L., 
Robillard, A. 2003. "A Prospective Study of Exposure to Rap Music Videos and African American Female Adolescents' Health." American Journal of Public Health 93: 437-440. 


\section{Appendix A}

\section{Screening Survey}

In-person Screening Questionnaire (to be used as a paper form completed during inperson recruitment phase)
a. How do you identify your gender?
b. How do you identify your sexuality?
c. How would you identify your race/ethnicity?
d. What is your age?
e. Do you live on a college campus (i.e dorms or sororities)? 


\section{Appendix B}

Demographic Face sheet

1. What is your age:

2. What race or ethnicity would you use to describe yourself? (Circle all that apply) Black or African American

Hispanic or

Latino Asian

White

Alaskan Native or American

Indian Native Hawaiian or

Pacific Islander

Other:

3. Which of the following best describes your sexual orientation? (Circle all that apply) Heterosexual or Straight Pansexual

Gay or Lesbian

Prefer not to say

Bisexual/Fluid

Other:

4. What is your relationship status?

Single Married Living with Partner Other:

5. Are you currently a student?

Yes No

6. What is your highest level of education?

Some high school Associate degree

High school degree Bachelor degree

Some college Graduate

degree Trade/vocational/technical training

7. What is your mother's highest level of education?

Some high school

Associate degree

73 
High school degree Bachelor degree

Some college

Graduate

degree Trade/vocational/technical training N/A

8. What is your father's highest level of education?

Some high school

Associate degree

High school degree

Bachelor degree

Some college

Graduate degree 


\section{Appendix C}

\section{Interview Guide}

1. Just to start us off, can you tell me about what you knew about Tinder before you downloaded the app?

2. What made you decide to download the Tinder app?

3. If you are comfortable, do you mind walking me through your Tinder profile?

-How did you choose your pictures?

-How did you decide on what to put in your bio?

4. Who do you look to match with? Why?

5. When you are using Tinder, or maybe before you are using Tinder, have you thought about how you want to establish boundaries around sex and intimacy?

-If yes, how do you use your Tinder profile to communicate what you want or don't want in a potential hook-up or date?

6. Can you describe your experience using the Tinder app?

- How are conversations initiated?

-Can you give me an example of what these conversations look like?

7. How do you decide when to meet a 'match' in person?

8. Can you give me an example of a positive Tinder date? What about a negative Tinder date?

-How have these experiences influenced the way you use Tinder?

9. How often do you hook up with a Tinder match? (You can use whatever definition of 'hookup' you normally use). 
- Do you ever feel the men you match with have any sexual expectations?

- Do you feel like your experiences on Tinder may be different from men on Tinder?

10. Have you ever hooked up with a guy that you met outside of Tinder? (In- person, at a party, etc.)?

- If yes, how was this experience (or experiences) different than meeting someone on Tinder?

- If no, why do you think it has just been through Tinder?

11. Have you felt that the guys you met on Tinder were respectful in how they acted towards you? (Can you tell me about what you mean by respectful?)

- $\quad$ (if they hooked up) Did you feel differently about that guy after hooking up? Did you feel that he treated you differently after a hookup?

- Is this similar or different from guys you met other ways?

12. Who knows you are on Tinder? Your friends? Parents? Why did you make that decision?

13. How do you think Tinder might influence the ways in which you initiate potential intimate relationships? 